\title{
RESPIRATORY THERAPIES FOR AMYOTROPHIC LATERAL SCLEROSIS: A PRIMER
}

\author{
KIRSTEN L. GRUIS, MD, MS, ${ }^{1}$ and NOAH LECHTZIN, MD, MHS ${ }^{2}$ \\ ${ }^{1}$ Department of Neurology, University of Michigan, 1C327 UH, EMG Lab, SPC 5036, 1500 E. Medical Center Drive, Ann Arbor, \\ Michigan 48109, USA \\ ${ }^{2}$ Pulmonary and Critical Care Medicine, Johns Hopkins University School of Medicine, Baltimore, Maryland, 21205, USA \\ Accepted 12 December 2011
}

ABSTRACT: Respiratory complications are a common cause of morbidity and mortality in amyotrophic lateral sclerosis (ALS). Treatment of respiratory insufficiency with noninvasive ventilation (NIV) improves ALS patients' quality of life and survival. Evidence-based practice guidelines for the management of ALS patients recommend treatment of respiratory insufficiency with NIV as well as consideration of insufflation/exsufflation to improve clearance of airway secretions. Despite these recommendations respiratory therapies remain underused. In this review we provide a practical guide for the clinician to prescribe and manage respiratory therapies for the patient with ALS.

Muscle Nerve 46: 313-331, 2012

Respiratory failure with or without pneumonia is the most common cause of death in amyotrophic lateral sclerosis (ALS). ${ }^{1,2}$ Reduced ventilation results in part from respiratory muscle weakness secondary to progressive motor neuron degeneration. Respiratory muscle weakness is defined as the inability of respiratory muscles to generate normal levels of pressure and airflow during inspiration and expiration. ${ }^{3}$ This leads to respiratory insufficiency, which is defined as inadequate pulmonary ventilation to the point that gas exchange is impaired, resulting in carbon dioxide retention, hypoxemia, and frank respiratory failure. ${ }^{3,4}$ In general, patients with ALS are able to compensate for respiratory muscle weakness for a period of time, but at some point they develop respiratory insufficiency and eventual respiratory failure.

Treatment of ALS patients with symptoms of respiratory insufficiency with noninvasive ventilation

Abbreviations: A/C, assist control; AAN, American academy of neurology; ABG, arterial blood gas; ACCP, American college of chest physicians; ALS, amyotrophic lateral sclerosis; BPM, breaths per minute; CM, centimeters; CPAP, continuous positive airway pressure; DPS, diaphragmatic pacing stimulator; EPAP, expiratory positive airway pressure; $\mathrm{FEF}_{\mathrm{Max}}$, maximum forced expiratory flow; FRC, functional residual capacity; FVC, forced vital capacity; HFCWO, high frequency chest wall oscillation; IPAP, inspiratory positive airway pressure; MI-E, mechanical insufflation-exsufflation; MIP, maximum inspiratory pressure; MEP, maximum expiratory pressure; NIV, noninvasive ventilation; $\mathrm{PaCO} 2$, partial pressure of arterial carbon dioxide; PAP, positive airway pressure; PCF, peak cough expiratory flow; PEEP, positive end-expiratory pressure; PEFR, peak expiratory flow rate; PPV, positive predictive value; PS, pressure support; S, spontaneous; S/T, spontaneous timed; SaO2, oxygen saturation; SD, standard deviation; SIMV, synchronized intermittent mandatory ventilation; SNIP, maximal sniff nasal pressure; SVC, slow vital capacity VC, vital capacity

Key words: amyotrophic lateral sclerosis; mechanical insufflationexsufflation; noninvasive ventilation; practical guide; respiratory therapy

Correspondence to: K. L. Gruis; e-mail: kgruis@umich.edu

(c) 2012 Wiley Periodicals, Inc.

Published online 6 January 2012 in Wiley Online Library (wileyonlinelibrary. com). DOI 10.1002/mus.23282

Respiratory Therapies for ALS
(NIV) appears to improve survival ${ }^{5-9}$ (Table 1) and quality of life, ${ }^{10,11}$ which may be attributable to a slower rate of pulmonary function decline. ${ }^{7,10,12}$ Supported by these data, both the 1999 and 2009 American Academy of Neurology (AAN) ALS practice parameters recommend consideration of NIV treatment for ALS patients with significant respiratory muscle weakness. ${ }^{13,14}$ Despite recommendations made in 1999 by both the AAN and the American College of Chest Physicians (ACCP) ${ }^{15}$ many ALS patients are not offered NIV therapy. ${ }^{16}$ Furthermore, despite recommendations about when to use respiratory aids for ALS, little information has been described in the literature about the practical aspects of initiating and managing respiratory therapies for ALS. The lack of literature that addresses the practical aspects of ALS respiratory care may make ALS clinicians reluctant to offer and prescribe respiratory therapies. The goal of this article is to provide a practical guide for the ALS clinician on the use of respiratory assistive devices and the prescription and management of these therapies for ALS patients.

\section{NONINVASIVE VENTILATION (NIV)}

A. NIV: When to Start. There is little evidence of explicit criteria on when NIV should be initiated, and expert opinions on the topic vary considerably. Nevertheless, the decision to prescribe NIV should be based on a combination of evidence of respiratory muscle weakness and respiratory symptoms.

Respiratory Muscles. Normal human inspiration at rest involves both the diaphragm and chest wall muscles. The external intercostals ${ }^{17}$ levator costae ${ }^{18}$ and parasternal intercostals ${ }^{19}$ are active with quiet breathing as measured by electrophysiology. The chest wall muscles work to elevate the sternum and ribs to expand both the anterior-posterior and transverse diameters of the chest and lungs. ${ }^{20}$ Thus human inspiration at rest is a combined effort of both the diaphragm and chest wall muscles. In contrast to the external intercostal muscles (inspiration), the internal intercostal muscles depress the ribs $^{17}$ and compress the chest. Both the 
Table 1. Studies demonstrating survival benefit for ALS patients using NIV.

\begin{tabular}{|c|c|c|c|c|c|}
\hline Author, year & $\begin{array}{l}\text { Study } \\
\text { design }\end{array}$ & NIV device & NIV started & Participants \& treatments & Findings \\
\hline Pinto, 1995 & NCT & Bi-level PAP & $\begin{array}{l}\text { Daytime hypercapnia } \\
\text { or hypoxia }\end{array}$ & 10 NIV 10 standard & $\begin{array}{l}\text { 3-year survival higher with } \\
\text { NIV }(87.5 \% \text { vs } 22.2 \%, P<.004)\end{array}$ \\
\hline $\begin{array}{l}\text { Aboussouan, } \\
1997\end{array}$ & Obs & $\begin{array}{l}\text { BiPAP }^{\circledR} ; \\
\text { ST mode or } \\
\text { PLV-100 }\end{array}$ & $\begin{array}{l}\text { Daytime orthopnea, } \\
\text { hypercapnia or both }\end{array}$ & $\begin{array}{l}21 \mathrm{NIV} \geq 4 \mathrm{~h} \text { nocturnal } \\
18 \text { intolerant }\end{array}$ & $\begin{array}{l}\text { Median survival } 2 \text { months in } \\
\text { those NIV intolerant, } 15 \text { months } \\
\text { NIV tolerant }(P<0.001)\end{array}$ \\
\hline Kleopa, 1999 & Obs & Bi-level PAP & $\begin{array}{l}\text { Respiratory symptoms, } \\
\text { FVC }<50 \% \text { predicted, } \\
\text { or FVC drop }>15 \% \\
\text { in } 3 \text { months }\end{array}$ & $\begin{array}{l}38 \mathrm{NIV}>4 \mathrm{~h} / \mathrm{d} 32 \\
\mathrm{NIV}<4 \mathrm{~h} / \mathrm{d} 52 \\
\text { refused NIV }\end{array}$ & $\begin{array}{l}\text { Mean survival } 14.2 \mathrm{mo}>4 \mathrm{~h} / \mathrm{d}(\mathrm{p}<0.001) \text {, } \\
7.0 \mathrm{mo}<4 \mathrm{~h} / \mathrm{d}(P=0.038) \\
4.6 \mathrm{mo} \text { refused NIV }\end{array}$ \\
\hline Gruis, 2006 & Obs & $\begin{array}{l}\text { Bi-level PAP; } \\
\text { S mode }\end{array}$ & $\begin{array}{l}\text { Respiratory symptoms and } \\
\text { FVC }<50 \% \text { or MIF } \\
<-60 \mathrm{~cm} \text { water }\end{array}$ & $\begin{array}{l}18 \text { NIV } \geq 4 \text { h/nocturnal } \\
19 \text { intolerant }\end{array}$ & $\begin{array}{l}\text { NIV tolerant decreased risk of } \\
\text { death }(\mathrm{HR} 0.23) 95 \% \mathrm{Cl}(0.10,0.54)\end{array}$ \\
\hline Bourke, 2006 & RCT & $\begin{array}{l}\text { VPAP }^{\circledR} \text { STII; } \\
\text { ST mode }\end{array}$ & $\begin{array}{l}\text { Orthopnea \& MIP }<60 \% \\
\quad \text { or hypercapnia }\end{array}$ & 22 NIV 19 standard & $\begin{array}{l}\text { Median survival benefit } 205 \text { days } \\
\text { with NIV }(P=.006) \text {. }\end{array}$ \\
\hline
\end{tabular}

NCT, nonrandomized controlled clinical trial; Obs, observational study; RCT, randomized controlled clinical trial; NIV, noninvasive positive-pressure ventilation; PAP, positive airway pressure; FVC, forced vital capacity; MIP, maximum inspiratory pressure; MIF, maximum inspiratory force (MIP, MIF, or negative inspiratory force are often used interchangeably); PLV-100, volume-controlled portable ventilator in assist-control mode (Life Care Products, Lafayette, CO); BiPAP ${ }^{\circledR}$ (Respironics, Inc., Murrysville, PA); VPAP ${ }^{\circledR}$ STIl (ResMed, UK Ltd, Abingdon, UK); ST, spontaneous timed mode; S, spontaneous mode; HR, hazard ratio; $\mathrm{Cl}$, confidence interval; $\mathrm{cm}$, centimeters; $h$, hours; mo, months.

internal intercostals and abdominal muscles are respiratory muscles of active expiration.

Although the force generated by the diaphragm versus other chest wall inspiratory muscles cannot be measured in isolation with standard tests of respiratory function (described in the next section), some information can be gained by the differences in motor innervation. The intercostal and levator costae muscles are innervated by corresponding intercostal nerves that originate from the ventral thoracic nerve roots. The external intercostals are innervated predominately by the upper thoracic nerve roots, T2-6, while the diaphragm is innervated by the C3-5 roots. Electrodiagnostic evidence of denervation of $\mathrm{T} 5$ innervated paraspinal myotomes, as well as the diaphragm, but not limb muscles [biceps brachii (C5-6) and tibialis anterior] demonstrate high specificity and positive predictive value for an abnormal forced vital capacity $<80 \%$ in ALS patients. ${ }^{21}$ Therefore, denervation of the diaphragm, but also the upper thoracic myotomes, which are known to innervate intercostal muscles, is associated with reduced respiratory function in ALS.

Measuring Respiratory Muscle Strength. To guide initiation of NIV therapy it is important to assess respiratory muscle strength. Respiratory muscle weakness can be assessed easily with noninvasive hand-held devices. The most common methods include vital capacity (VC) (Fig. 1), maximum inspiratory mouth pressure (MIP), and maximum expiratory mouth pressure (MEP). Vital capacity can be measured by 2 different methods: forced vital capacity (FVC) and slow vital capacity (SVC). With the FVC maneuver, the patient is instructed to take a maximum inspiration, occlude the nares, and then blow all the air out as fast and completely as possible. The slow vital capacity (SVC) is similar in that the patient is instructed to maximally inspire, occlude the nares, and then blow all the air out as completely as possible, but not as fast as possible. With both maneuvers, the patient exhales as much air as possible into a flow sensor. If the patient has significant lip weakness, preventing an adequate seal around the tube, it is common to lose some of the exhaled volume, resulting in an artificially low value. In this case, a mouthpiece or facemask can be placed on the flow sensor. The mouthpiece has a rubber flange that fits between the teeth and lips to provide a better seal.

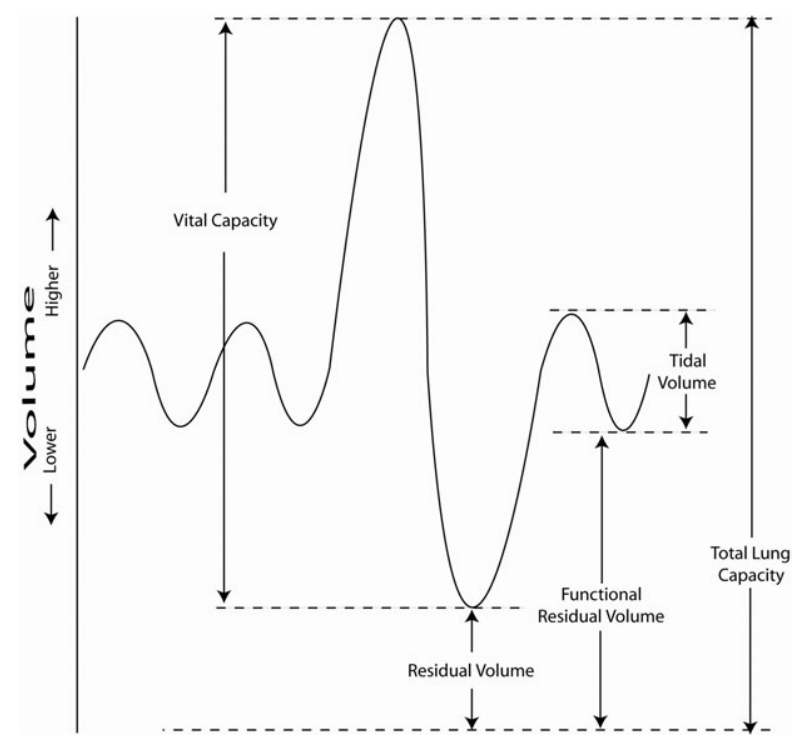

FIGURE 1. Lung Volumes.

MUSCLE \& NERVE September 2012 
Two common mouthpieces include the AirLife ${ }^{\mathrm{TM}}$ adult rubber mouthpiece, and the ComFit ${ }^{\mathrm{TM}}$ disposable mouthpiece. The MIP and MEP are measured starting at functional residual capacity (FRC) (Fig. 1) at the end of expiration of quiet breathing. At FRC the outward pull of the chest wall is balanced against the inward pull of the lungs. Thus measurement of MIP at FRC reduces any overestimate of pressure change from chest wall recoil to get the most accurate measurement of respiratory muscle force. ${ }^{22}$ The MIP is performed by having the mouth occluded with a mouthpiece connected to a pressure transducer. The patient then expires through the nose, and the nares are then occluded while the patient performs a maximum inspiratory effort for 2-3 s. The MEP is performed in the same manner, only the nares are occluded, and maximum expiratory effort is performed for 2-3 s. The peak inspiratory pressure over one second is the recorded MIP, and the peak expiratory pressure over $1 \mathrm{~s}$ is the MEP. The maneuver is repeated 3 times or until 2 similar measurements obtained, as the patient may have learned improvement with the MIP/MEP procedure. The MIP and MEP are designed to be isometric measurements of inspiratory and expiratory muscle force. Respiratory efforts against an occluded circuit can be uncomfortable and awkward, and therefore artificially low measures may be obtained. Also, some patients with significant respiratory muscle weakness may be able to generate considerable pressure with their mouth muscles. This may lead to overestimation of MIP or MEP. A different, but complementary test to the MIP is the maximal sniff nasal pressure (SNIP). With the SNIP, a plug is placed in 1 nostril, the patient breathes normally with the mouth closed and then the other nostril is occluded while the patient performs 10 maximum sniffs. Sniffing maneuvers are more reproducible than the sustained efforts used for measuring MIP, and problems related to mouth weakness are avoided. The FVC and SVC are measured with a spirometer and are adjusted for age, gender, and height. They are displayed as the actual value in liters and the adjusted value as the percent predicted. The MIP and SNIP are also recorded as the exact value with negative centimeters $(\mathrm{cm})$ of $\mathrm{H}_{2} \mathrm{O}$ for $\mathrm{MIP}$ and positive $\mathrm{cm}$ of $\mathrm{H}_{2} \mathrm{O}$ for MEP. The MIP, MEP, and SNIP are affected by gender and age and may also be presented as percent predicted. Normal ranges based on age and gender for MIP, MEP and SNIP are found in Table $2 .^{22}$ It is worth noting that other studies of MIP and MEP have yielded a large range for normal values. ${ }^{23}$

FVC measured in the upright position can detect mild respiratory muscle weakness early in

\begin{tabular}{|c|c|c|c|}
\hline Age & $\begin{array}{c}\text { MIP } \mathrm{cm} \mathrm{H} \mathrm{H}_{2} \mathrm{O} \\
\text { Mean }(\mathrm{SD}), \\
{[<60 \% \text { predicted }]^{\star}}\end{array}$ & $\begin{array}{c}\text { MEP cm } \\
\mathrm{H}_{2} \mathrm{O} \\
\text { Mean (SD) }\end{array}$ & $\begin{array}{c}\text { SNIP cm } \\
\mathrm{H}_{2} \mathrm{O} \text { Mean (SD), } \\
{[<32 \% \text { predicted }]^{\dagger}}\end{array}$ \\
\hline \multicolumn{4}{|l|}{ Men: } \\
\hline $20-35$ & $-110(27),[-65]$ & $128(32)$ & 117 (30), [37] \\
\hline $36-50$ & $-105(21),[-62]$ & $132(34)$ & 105 (25), [33] \\
\hline $51-65$ & $-104(22),[-61]$ & $129(22)$ & 112 (16), [35] \\
\hline $66-80$ & -83 (23), [-49] & $103(32)$ & 91 (22), [28] \\
\hline \multicolumn{4}{|l|}{ Women: } \\
\hline $20-35$ & - 78 (18), [-46] & $84(16)$ & 84 (15), [26] \\
\hline $36-50$ & $-87(21),[-51]$ & $95(25)$ & 94 (21), [29] \\
\hline $51-65$ & -80 (17), [-47] & $81(16)$ & 84 (18), [26] \\
\hline $66-80$ & $-58(16),[-34]$ & $69(18)$ & 76 (11), [24] \\
\hline
\end{tabular}

Normal values. ${ }^{22}$

*Orthopnea and MIP $<60 \%$ predicted used as criteria to start NIV in a randomized controlled study. ${ }^{9}$

${ }^{+}$SNIP $<32 \%$ predicted associated with $85 \%$ specificity and $81 \%$ sensitivity in predicting hypercarbic respiratory insufficiency. ${ }^{29}$

MIP, maximum inspiratory pressure; MEP, maximum expiratory pressure;

SNIP, maximal sniff nasal pressure; SD, standard deviation.

the disease course, as $71-85 \%$ of ALS patients have an abnormal FVC $(<80 \%)$ at the time of presentation. ${ }^{24-26}$ However, supine FVC $^{27}$ and MIP appear to decrease earlier in the ALS disease course than upright FVC. $^{25,28}$ ALS patients with respiratory symptoms have lower mean FVC than those without respiratory symptoms, $56 \%$ vs. $76 \% .{ }^{25}$ However, Fallat et al. demonstrated that as many as $64 \%$ of ALS patients with an FVC $<50 \%$ may have mild or no significant respiratory symptoms. ${ }^{24}$ Therefore, as early as the late 1970s, it was recommended that spirometry, including vital capacity, be measured serially in ALS patients to detect respiratory muscle weakness irrespective of symptoms.

There is considerable debate about which measure of respiratory muscle weakness will optimally detect impending respiratory insufficiency. The clinician may be compelled to start NIV before daytime hypercarbia or symptomatic respiratory muscle weakness ensues to prevent or delay this occurrence. However, there are no randomized controlled studies that address whether starting NIV therapy earlier, before daytime hypercapnia or symptoms of orthopnea, is beneficial to prevent respiratory failure or to prolong survival. It also may be quite possible that ALS patients without respiratory symptoms may abandon NIV therapy. Both the SVC $<50 \%$ predicted and MIP $25 \%$ predicted have high specificity, $89 \%$, and $83 \%$ respectively, in predicting hypercarbic respiratory failure, but lower sensitivity, $53 \%$ and $55 \%$, respectively. ${ }^{29}$ If the MIP cutoff for predicting respiratory failure were increased to $45 \%$ of predicted, the specificity of the test dramatically decreased to $56 \%$. A SNIP $<32 \%$ of predicted had similar specificity, $85 \%$, but with higher sensitivity, $81 \%$, in predicting current hypercarbic respiratory failure. ${ }^{29}$ However, 
when a diagnostic test has a higher sensitivity, it also is more likely to include false positive results; therefore, the positive predictive value (PPV) or proportion of subjects with a positive test result who are correctly diagnosed becomes a more useful assessment of test precision. The positive predictive value (PPV) or the proportion of ALS patients with an abnormal SNIP or SVC who are correctly diagnosed with hypercarbic respiratory insufficiency is essentially the same: SNIP $<32 \%$ $\mathrm{PPV}=68 \%$ and $\mathrm{SVC}<50 \% \mathrm{PPV}=67 \% .{ }^{29}$ The SNIP therefore becomes more useful to rule out hypercarbic respiratory failure when the SNIP is $>32 \%$. Importantly, no test of respiratory muscle strength (SVC, MIP, MEP, or SNIP) had significant positive predictive power to detect hypercarbic respiratory insufficiency in those ALS patients with significant bulbar dysfunction. ${ }^{29}$ Others have indicated the SNIP actually underestimates inspiratory muscle strength, as the mean MIP remains higher than the mean SNIP in ALS patients with moderately severe respiratory impairment, with a mean VC around $50 \%{ }^{30}$ The 2 tests measure inspiratory muscles in different ways; the SNIP is a fast contraction, while the MIP is a sustained isometric contraction of inspiratory muscles. ${ }^{30}$ Isometric muscle force of limb muscles is a standard measure of muscle function for ALS, ${ }^{31}$ thus isometric measures with MIP and MEP would suggest a meaningful measurement of respiratory muscle function.

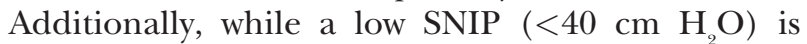
recommended as a trigger to consider starting NIV in the more recent 2009 AAN practice parameter, ${ }^{14}$ it is not a measure supported by evidence from a randomized controlled study. It is not currently recommended by the American College of Chest Physicians (ACCP) and is not recognized as a trigger for NIV by Medicare guidelines.

ALS Patient Symptoms and Measures of Respiratory Muscle Function at NIV Initiation. Initial studies of NIV for ALS report beginning NIV when patients have either (1) objective evidence of respiratory insufficiency with daytime hypercapnia, (2) respiratory symptoms including orthopnea, or (3) FVC $<50 \%$ or $15 \%$ drop in FVG over a 3-month period (Table 1). ${ }^{5-7}$ All 3 studies published in 1999 or earlier (Table 1) reported improved survival in ALS patients who were tolerant to NIV therapy. However, 1 study was retrospective, and the other 2 prospective studies did not randomize patients to NIV treatment. Nevertheless, these findings were compelling enough that the 1999 AAN practice parameter provided a guideline recommending that NIV be provided to ALS patients with respiratory symptoms or FVC $<50 \%{ }^{13}$ Additionally, the ACCP provided a consensus recommendation in 1999 that NIV be initiated for patients with ALS (and several other neuromuscular disorders) with symptoms of "fatigue, dyspnea, morning headache, etc." and one of the following: hypercapnia with $\mathrm{PaCO}_{2}$ (partial pressure of arterial carbon dioxide) $\geq 45 \mathrm{mmHg}$, nocturnal oximetry demonstrating oxygen saturation $\leq 88 \%$ for 5 consecutive minutes, MIP $<-60 \mathrm{~cm} \mathrm{H}_{2} \mathrm{O}$, or $\mathrm{FVC}<50 \%$ predicted. $^{15}$ Importantly, the ACCP guidelines for initiating NIV were adopted by Medicare and subsequently other medical insurance providers. Therefore in ALS, documentation of symptoms of respiratory muscle weakness and 1 of the aforementioned abnormal objective physiologic measurements of respiratory muscle weakness are required for the initial prescription of NIV. It is important for the ALS clinician to know that a polysomnogram (sleep study) is NOT required to start NIV in ALS patients who meet the criteria outlined by the ACCP.

In an attempt to determine the optimal measurements of respiratory muscle weakness to guide initiation of NIV and optimize quality of life and NIV compliance, Bourke et al. prospectively followed ALS patients with periodic VC, MIP, MEP, SNIP, daytime arterial blood gas and polysomnograms for 1 year. ${ }^{10}$ ALS patients were offered NIV if they met any one of the following criteria: (1) orthopnea (supine breathlessness), (2) daytime sleepiness or unrefreshing sleep in the presence of sleep-disordered breathing or respiratory muscle weakness with MIP and SNIP $<80 \%$ predicted, (3) daytime hypercapnia with $\mathrm{PaCO}_{2}>45 \mathrm{mmHg}$, (4) nocturnal oxygen desaturation with $\mathrm{SaO} 2$ (oxygen saturation) $<90 \%$ for $\geq 5 \%$ of the night, or (5) apnea-hypopnea index $>10$ events per hour of sleep. The study demonstrated that orthopnea was the symptom associated with the most significant improvement in quality of life, while sleep symptoms were less specific. The apnea-hypopnea index was not at all useful to guide initiation of NIV treatment. $^{10}$ Therefore, daytime sleepiness and poor sleep are not always associated with respiratory muscle weakness, and the clinician should interpret these symptoms with some caution.

Some experts have suggested that nocturnal oxygen desaturation is an early finding of respiratory muscle weakness and precedes significant daytime respiratory symptoms and hypercarbia. ALS patients who were started on NIV after demonstrating a small drop in nocturnal oxygen saturation (4\% below the mean nocturnal oxygen saturation) with normal arterial blood gas assessment had improved survival compared with historical controls who were started on NIV with an abnormal arterial blood gas. ${ }^{32}$ This suggests that an individual with a mean nocturnal oxygen saturation of $96 \%$ who drops to $92 \%$ should be started on NIV. 
It is difficult to believe that such a small change in oxygen saturation is clinically meaningful. Perhaps the findings could be attributed simply to starting NIV before development of an abnormal arterial blood gas measurement. Additionally, at least 1 study has demonstrated that ALS patients with orthopnea, a symptom that would suggest NIV initiation would improve quality of life, reported no abnormal drop in nocturnal oxygen saturation (abnormal measured as $<90 \%$ for $\geq 5 \%$ of the night). ${ }^{10}$ Furthermore, the same study demonstrated that all ALS patients with abnormal nocturnal oxygen saturation also reported orthopnea, and several ALS patients with orthopnea did not have abnormal nocturnal oxygen desaturation. ${ }^{10}$ This latter finding suggests that significant nocturnal oxygen desaturation did not precede development of orthopnea. Taken together, these findings indicate that nocturnal oxygen desaturation is unlikely to provide additional information to the clinician on when to initiate NIV. Lastly, in terms of practicality, Medicare uses the ACCP guideline for nocturnal oxygen desaturation, $<88 \%$ for 5 sustained min, to prescribe NIV for ALS. Therefore, a small drop in nocturnal oxygen saturation in isolation will not allow for NIV initiation by Medicare guidelines.

The first randomized controlled study of NIV for ALS patients used a primary outcome of quality of life and secondary outcome of survival. ${ }^{9}$ Fortyone ALS patients were admitted to the hospital and randomized to NIV or standard of care treatment if they had symptoms of orthopnea and a MIP $<60 \%$ predicted, or symptoms associated with daytime hypercapnia $\mathrm{PaCO}_{2}>45 \mathrm{mmHg}$. Patients in the NIV group had a significant improvement in quality of life and a median survival benefit of 205 days (nearly 7 months). ${ }^{9}$ Although VC was not used as a criterion to initiate NIV, the mean VC was only $56 \%$ in the NIV group and $49 \%$ in the standard of care group at the time of treatment randomization, indicating that these ALS patients had significant reductions in VC. Furthermore, it is important to note that the randomized controlled study used an MIP of $<60 \%$ predicted, not an absolute MIP $<-60 \mathrm{~cm} \mathrm{H}_{2} \mathrm{O}$. For many patients over the age of 65 , a normal MIP may be around $-50 \mathrm{~cm} \mathrm{H}_{2} \mathrm{O}$ for women or $-80 \mathrm{~cm} \mathrm{H}_{2} \mathrm{O}$ for men (Table 2), ${ }^{22}$ corresponding to a $<60 \%$ predicted

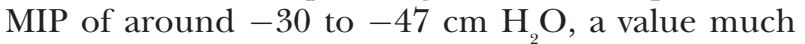
lower than the guideline from the ACCP's MIP $\left(<-60 \mathrm{~cm} \mathrm{H} \mathrm{H}_{2} \mathrm{O}\right)$. Importantly, this value $(<-60$ cm $\mathrm{H}_{2} \mathrm{O}$ ) was not supported by a randomized controlled study. Additionally, the evidence demonstrating a survival advantage for ALS patients using NIV applies to patients with significant respiratory muscle weakness with a mean $\mathrm{FVC}=56 \%$, MIP $=$
$31 \%$ predicted, and SNIP $=23 \%$ predicted.$^{9}$ It remains uncertain whether initiating NIV when patients are without daytime hypercarbia or orthopnea and with an MIP $>60 \%$ predicted improves survival. Randomized controlled studies are needed to address this question, particularly since retrospective or nonrandomized studies have suggested that starting NIV earlier in the disease course may improve outcomes. ${ }^{12,32,33}$

\section{Conclusions}

1 ALS patients should have VC (FVC or SVC), MIP, and MEP assessed approximately every 2-4 months irrespective of respiratory symptoms. Supine FVC should be considered, as it can detect milder respiratory muscle weakness.

2 SNIP may also be considered, as a SNIP $>32 \%$ likely excludes the diagnosis of hypercarbic respiratory insufficiency but is not a replacement for MIP.

3 NIV should be offered if an ALS patient has (1) orthopnea and MIP $<60 \%$ predicted or (2) $\mathrm{PaCO}_{2} \geq 45 \mathrm{mmHg}$ and symptoms related to hypercapnia.

4 NIV should be considered in ALS patients with (1) symptoms of orthopnea or respiratory muscle weakness and (2) MIP $<-60 \mathrm{~cm} \mathrm{H}_{2} \mathrm{O}$ or FVC $<50 \%$.

5 NIV should be considered in ALS patients without respiratory symptoms and an FVC $<50 \%$.

6 Nocturnal oxygen saturation and polysomnogram do not appear to provide additional information beyond an assessment of respiratory symptoms and tests of respiratory muscle strength (FVC and MIP) in deciding whether to initiate NIV for ALS patients.

\section{B. NIV Device Type. Bi-level Positive Airway Devi-} ces. Bi-level positive airway pressure (PAP) machines are the most commonly used devices to manage respiratory weakness in ALS and are the best studied (Table 1). Bi-level PAP machines are often referred to by trade names. Examples include the following: BiPAP ${ }^{\circledR}$ (Philips Respironics, Inc., Murrysville, PA) and VPAP ${ }^{\circledR}$ (ResMed Corp, San Diego, CA). The machines are set to deliver a specific inspiratory airway pressure (IPAP) and expiratory airway pressure (EPAP), similar to a pressure-controlled mechanical ventilator. The difference in pressure between IPAP and EPAP represents the level of pressure support. Thus, identical absolute increases in IPAP and EPAP do not alter the pressure support provided. Typically, bi-level PAP has 2 modes: spontaneous (S) and spontaneous/timed (ST). In both the S and ST mode, the bi-level PAP is triggered to provide 
IPAP when the user generates a small inspiratory flow. The machine then provides the IPAP to support inhalation for a maximum of 3 seconds, or when air flow significantly decreases, indicating the end of inspiration, and the machine returns to EPAP. For the most part, the trigger for cycling from IPAP to EPAP is pre-set and cannot be changed by the clinician or patient. The patient's spontaneous breathing drives the machine to cycle between IPAP and EPAP, and this provides some degree of comfort and control over the NIV device. In the ST mode, the machine works as described in the $\mathrm{S}$ mode but additionally can provide a machine-triggered breath if the patient falls below the minimum number of breaths per minute, as set by the clinician. In the ST mode, the provider can set the duration of the machine-triggered breath, but the IPAP pressure setting delivered by the machine or the patient's spontaneous breathing is the same. It is our experience that many ALS patients can trigger the bi-level PAP machine in the $\mathrm{S}$ mode and may not require machine-triggered breaths in the ST mode. However, some patients may have abnormal central respiratory drive and will benefit from having a set backup respiratory rate. Also, patients with very severe inspiratory muscle weakness may not be able to trigger the bi-level PAP machine and will require a set rate. The clinician must make the family aware that the NIV machine set in ST mode will continue to provide assisted breaths to an ALS patient after death. We have had patients die in their sleep, yet the family was unaware, as the NIV machine continued to cycle as if the patient was breathing. Although bi-level PAP machines were used in the ST mode in several studies including a randomized controlled trial, ${ }^{6,9}$ no information was provided on machine-triggered breaths or the rate used. A least 1 observational study demonstrated a survival benefit in those tolerant of bi-level PAP using the $\mathrm{S}$ mode (Table 1). ${ }^{8}$ There are no randomized controlled studies comparing different modes or types of bi-level PAP devices for ALS.

Autotitrating NIV devices are relatively new and designed as alternatives to standard bi-level PAP. With the autotitrating NIV, the clinician can specify a target tidal volume and a range for the maximum and minimum IPAP. Examples of the autotitrated NIV include the BiPAP ${ }^{\circledR}$ AVAPS (Phillips Respironics), AutoVPAP ${ }^{\circledR}$ (ResMed), and the Trilogy mechanical ventilator (Phillips Respironics) in the AVAP mode. In theory, the auto-titrated NIV may have advantages with respect to NIV tolerance by providing only the IPAP required to support the target tidal volume. Additionally, in asymptomatic patients, this provides an objective target for titration. However, in a randomized cross-over study comparing standard bi-level NIV with auto-titrated NIV in patients with respiratory insufficiency from neuromuscular disease, the auto-titrated NIV provided less ventilatory support with a statistically significant decrease in mean minute volume ventilation and an increase in mean carbon dioxide. Furthermore, the auto-titrated NIV was not associated with improved patient self-reported tolerance. ${ }^{34}$ Thus far, there is no clear advantage for using auto-titrated NIV over standard NIV for respiratory insufficiency from neuromuscular disease.

Portable Ventilators. When portable ventilators capable of volume cycled ventilation are used, the term mechanical ventilation is typically applied. Mechanical ventilation with a portable ventilator can be used non-invasively just like a bi-level PAP machine or invasively with a tracheostomy in the outpatient setting. Portable ventilators can be set to provide the patient with a set amount of pressure (pressure support ventilation) or a set amount of volume (volume controlled ventilation) with each breath. Experts debate whether pressure support or volume controlled mode is best for patients with ALS, but there is no evidence to support one over the other. A randomized cross-over study exposed patients with hypercarbic respiratory insufficiency from a variety of disorders to both pressure and volume controlled NIV with mechanical ventilators. Both modes significantly improved gas exchange as measured by arterial blood gas, and the patients indicated no preference for pressure or volume controlled NIV. ${ }^{35}$ There are no randomized, controlled studies that compare bilevel PAP machines and portable ventilators. One study from 1997 reported ALS patients chose a bilevel PAP device when given the option of bi-level PAP or volume-controlled ventilator. ${ }^{6}$ However, since 1997, portable ventilators and bi-level PAP devices have evolved. The portable ventilators have become smaller and more user-friendly than the devices that existed a decade ago.

While portable ventilators are more complicated than bi-level PAP machines in regard to ease of set-up, these devices do allow for more options in administration of NIV. The portable ventilator allows for more control of the flow trigger and inspiratory and expiratory time. The flow trigger allows for more sensitivity and thus less air movement on the part of the ALS patient to trigger the ventilator for a breath. The inspiratory and expiratory time adjustments allow more control as to how long the ALS patient receives positive airway pressure during each phase. For example, patients may be accustomed to taking small, frequent breaths, and if they are suddenly forced to take less frequent but larger breaths with NIV, they may be uncomfortable. It is unclear if these additional 
adjustments with a portable ventilator offer meaningful advantages to the ALS patient over a bi-level PAP machine, aside from comfort in some cases.

Portable ventilators come with an internal battery that allows the user more freedom with the device, while the bi-level PAP machines must use an external battery pack or power adapter if they are used in a motor vehicle. If an ALS patient uses the bi-level PAP throughout the night and day, power failure of the device could lead to death. ${ }^{36}$ Both the bi-level PAP and portable ventilator can be attached to a power wheelchair with the appropriate brackets, and the wheel chair battery can be used as a power source. The clinician should contact the ALS patients' wheel chair provider to order these attachments.

Oxygen Therapy. Importantly, oxygen therapy has been demonstrated to worsen respiratory symptoms and carbon dioxide retention in patients with neuromuscular respiratory insufficiency, resulting in hypercapnic coma or respiratory arrest. ${ }^{37}$ Supplemental oxygen as low as 0.5 to $2 \mathrm{~L} / \mathrm{min}$ has been demonstrated to exacerbate carbon dioxide retention. $^{38}$ ALS patients who may require oxygen therapy for a non-ALS diagnosis such as pulmonary or cardiac disease should use oxygen in conjunction with NIV.

\section{Conclusions}

1 Bi-level PAP devices used in the spontaneous/ timed or spontaneous mode for ALS patients with symptomatic respiratory muscle weakness are associated with a survival benefit.

2 The spontaneous/timed mode requires the provider to set the breaths per minute (BPM) rate. If this mode is selected, a standard initial rate of 6-10 BPM is a reasonable value to avoid discomfort from excessive machine-triggered breaths, but it should be titrated to the individual.

3 Portable ventilators capable of volume cycled ventilation are an alternative to bi-level PAP machines to administer NIV to ALS patients.

4 ALS patients who rely on NIV need to have an alternative power source available. ALS patients and caregivers should know how to contact an on-call respiratory therapist to assist with any dysfunction of an NIV device.

5 Oxygen therapy is not needed and should be avoided in nearly all ALS patients with respiratory insufficiency.

C. NIV- How to Start and Titrate. Background. To alleviate dyspnea or orthopnea, NIV must provide enough support to off-load the work of breathing. Initial settings are often relatively low, with an IPAP of $8-10 \mathrm{~cm}$ of $\mathrm{H}_{2} \mathrm{O}$ and EPAP of $3-5 \mathrm{~cm} \mathrm{H}_{2} \mathrm{O}$ to allow the patient to become accustomed to NIV. ${ }^{39}$ The IPAP is then increased as needed to alleviate symptoms or improve gas exchange as measured by arterial blood gas while maintaining patient tolerance to NIV. ${ }^{9}$ The normal respiratory system only needs to decrease intrathoracic pres-

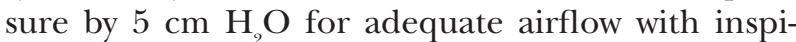
ration. ${ }^{40}$ Therefore, applying $4-5 \mathrm{~cm} \mathrm{H}_{2} \mathrm{O}$ pressure support to the system is reasonable to assist weakened muscles of inspiration, assuming chest wall and lung compliance are relatively normal. If these structures have decreased compliance, the patient will require higher pressure support. However, if the provider increases the pressure support beyond what is needed to support quiet breathing, the patient may feel uncomfortable secondary to overinflation of the lungs. At the time NIV is started, patients may be using accessory respiratory muscles, such as the sternocleidomastoids, with quiet breathing in addition to routinely used inspiratory muscles: the diaphragm and external intercostal muscles. ${ }^{27}$ Accessory muscle use often abates in the upright and supine positions with NIV, demonstrating its effectiveness. ${ }^{6,41}$

Where to Start NIV. In the only randomized controlled study of NIV for ALS, patients were admitted to the hospital for NIV initiation. ${ }^{9}$ We have successfully admitted ALS patients to the hospital to titrate NIV. Evaluation and treatment of respiratory insufficiency is a valid reason for hospital admission and insurance approval. One alternative is titrating NIV for the ALS patient in a sleep laboratory. As discussed above, polysomnography plays no significant role in determining when to start NIV, but it may be used to guide titration of initial NIV pressure settings. This would require significant discussion with the sleep laboratory staff whose typical obstructive sleep apnea patient population is ambulatory without motor disabilities. Although portable, in-home polysomnography with oxygen saturation and transcutaneous carbon dioxide measurements are not readily available in the United States; these evaluations are performed in Europe. ${ }^{34}$ When patients with neuromuscular disorders requiring NIV were given the option of titrating NIV in a sleep laboratory or at home, the majority of patients chose home polysomnography. ${ }^{34}$ This finding is congruent with our experience that ALS patients are quite reluctant to spend a night in the sleep lab and prefer NIV initiation at home. The American Academy of Sleep Medicine has proposed best practices guidelines for the titration of NIV in a sleep laboratory for patients with stable hypoventilation syndromes. ${ }^{42}$ The ALS clinician should keep in mind that a sleep laboratory would not be appropriate for unstable ALS patients, and hospital admission would be advised. 
Additionally, the sleep laboratory may not have readily available appointments to accommodate ALS patients who require urgent NIV titration. One study demonstrated that nearly one-third of ALS patients started NIV therapy emergently. ${ }^{43}$ Importantly, emergent NIV initiation was not associated with poorer survival when compared with those ALS patients with nonemergent NIV initiation. ${ }^{43}$

A third alternative is initiating NIV in the outpatient clinic or home setting by the ALS clinician or respiratory therapist under ALS clinician direction. Observational studies have demonstrated that NIV initiated as an outpatient is associated with a survival benefit in those tolerant to NIV treatment. 6,8

NIV Pressure Settings. Little detailed information about titration of NIV for ALS has been published. In a randomized controlled study, initial NIV settings were selected to "optimize" nocturnal oximetry, "attempt to normalize" daytime gas exchange as measured by arterial blood gas $(\mathrm{ABG})$, and maintain ALS patient tolerance to NIV. ${ }^{9}$ No further description or results of oximetry were presented. In the same prospective study, after NIV initiation, subsequent titration was guided by daytime ABG and patient tolerance, but not nocturnal oximetry. ${ }^{9}$ Therefore the utility of nocturnal oximetry appears to be limited for monitoring NIV therapy. Additionally, in ALS one would expect measurement of nocturnal hypercapnia may be a more effective indicator of nocturnal ventilation support. In a retrospective study, NIV starting at $8 \mathrm{~cm}$ of $\mathrm{H}_{2} \mathrm{O}$ IPAP and $4 \mathrm{~cm}$ of $\mathrm{H}_{2} \mathrm{O}$ EPAP, with the IPAP increased as directed by patient symptoms, was associated with increased survival in those who tolerated the NIV despite the lack of ABG or oxygen saturation monitoring. ${ }^{8}$ Interestingly, pressure adjustments were often made early within the first year of use, although 4 of 18 tolerant subjects found the original pressure settings to be adequate for the duration of NIV use until death. ${ }^{8}$ No study has compared efficacy of NIV in those titrated by ABG, comfort, nocturnal oximetry, or capnography.

Titrating NIV to normalize daytime gas exchange as measured by ABG may be optimal. Nocturnal NIV has been demonstrated to improve daytime arterial hypercarbia and hypoxia in ALS patients. ${ }^{44}$ Thus nocturnal measurements of gas exchange may not be required. However, not all ALS clinics are able to measure an ABG in the outpatient setting easily, and ALS patients may refuse this painful procedure. Monitoring daytime exhaled end-tidal carbon dioxide or transcutaneous carbon dioxide with a capnograph may be a practical alternative. A capnograph is easy to use, relatively inexpensive, and portable, and it allows for convenient assessments in clinic or even in the patient's home. The disadvantage to end-tidal carbon dioxide measurement is that the accuracy may be limited when it is measured while the patient is using NIV, as increased airflow may artifactually dilute the exhaled concentration of carbon dioxide. Transcutaneous carbon dioxide is measured with a more expensive type of capnograph, where an infrared sensor is placed on the skin over a bony prominence or ear lobe such that measurements can be made while NIV is in place. In hemodynamically stable adults, transcutaneous carbon dioxide assessments correlated well with ABG partial pressure carbon dioxide measurements over a range of 26 to $71 \mathrm{mmHg}$. ${ }^{45}$

A possible alternative to using arterial blood gas assessment to guide NIV titration is to titrate NIV to maintain an adequate volume of ventilation based on weight. It has become a standard accepted value that a normal tidal volume in humans is around $6-8 \mathrm{ml} / \mathrm{kg}$, and optimal minute ventilation to maintain appropriate gas exchange is $6 \mathrm{~L} / \mathrm{min}$. The minute ventilation is simply the tidal volume times the respiratory rate. Unfortunately, most standard bi-level PAP type NIV machines do not measure user tidal volume or minute ventilation, but portable ventilators, even when used noninvasively, can record both values.

\section{Conclusion}

1 It is reasonable to begin NIV with $8 \mathrm{~cm} \mathrm{H}_{2} \mathrm{O}$ IPAP and $4 \mathrm{~cm} \mathrm{H}_{2} \mathrm{O}$ EPAP and increase the IPAP to alleviate symptoms, or to select the initial pressure based on improvement in daytime $\mathrm{ABG}$ and oximetry together with patient comfort.

2 Once initiated, NIV pressures should be titrated to comfort or daytime ABG.

3 When titrating to comfort, increases in IPAP of $2 \mathrm{~cm} \mathrm{H}_{2} \mathrm{O}$ are reasonable for each adjustment.

4 Increased NIV requirements are likely with time, and thus breathing comfort should be assessed serially.

D. NIV-Mask Interfaces. NIV mask interfaces include all those available for use with continuous positive airway pressure (CPAP). These interfaces are divided into 4 categories: nasal masks, nasal pillows/prongs, oronasal masks, and oral masks. Nasal masks are triangular in shape and fit over the entire nose, often with a portion of the mask resting on the forehead (Fig. 2). The mask is then held in place with straps around or a bracket over the head. Nasal pillows are tubes that fit onto the external nares (Fig. 3). The oronasal mask is often 

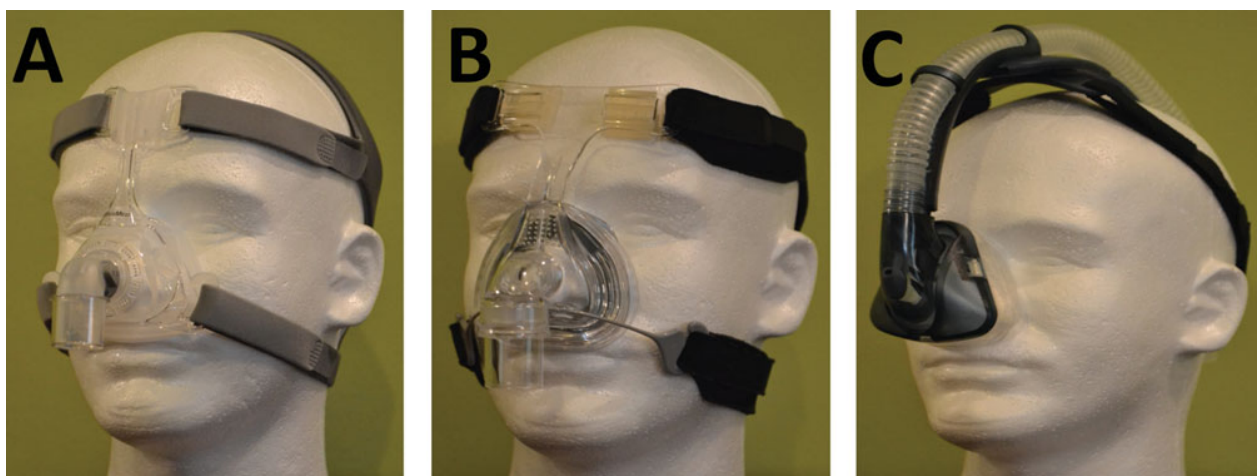

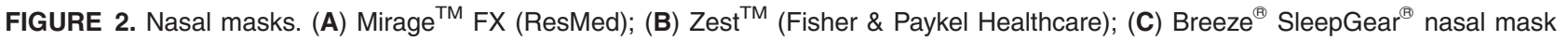
(Covidien-Puritan Bennett).

referred to as a full face mask, as it fits over the nose and mouth (Fig. 4). The oral mask is used only by means of the mouth and is not often used in ALS patients given the frequency of bulbar dysfunction.

There are no randomized controlled studies that compare any of the interfaces with respect to patient preference or tolerance in ALS. However, in a randomized controlled study comparing NIV to standard of care without NIV, both nasal and nasal oral masks were used. ${ }^{9}$ Literature reviews of the obstructive sleep apnea population demonstrate that nasal pillows are reported to be more comfortable than nasal masks. ${ }^{46}$ In a study of patients with hypercapnic respiratory insufficiency from either pulmonary or neuromuscular disorders who receive NIV with a mechanical ventilator, the nasal mask, nasal pillows, and oronasal mask interfaces were each used for a brief time period to assess mask preference and ABG improvement. ${ }^{35}$ All 3 mask types were associated with improved oxygenation and decreased hypercarbia, although it was slightly better with the nasal pillows and full face masks. In the same study, the nasal mask had the highest patient acceptance over the nasal pillows and full face mask. ${ }^{35}$
Headgear must be considered with respect to not only comfort, but also ease of placement and removal. Some headgears, such as those with a single piece head frame, are more conducive to onehanded operation than those with multiple straps. Although no studies have addressed this issue in ALS, the topic has been considered in stroke patients. In the acute stroke population, a group that may have significant upper limb weakness, patients were much quicker at placing and removing a single head frame headgear than a headgear with straps. Ease of use, however, did not necessarily correspond to comfort. ${ }^{47}$

We often use a nasal pillow system initially for comfort given that these mask interfaces have the least contact with the face. Nasal pillow systems that we have found to be successful include the Swift $^{\mathrm{TM}}$ FX (ResMed) (Fig. 3A), as it is very light weight with minimal pressure on the face and a minimal amount of straps on the head. This Swift ${ }^{\mathrm{TM}}$ FX is improved over the previous Mirage Swift ${ }^{\mathrm{TM}}$ II in that the tubing easily rotates with less chance of the tubing getting caught in the bed clothes and dislodging the interface. The Opus ${ }^{\mathrm{TM}}$ 360 (Fisher \& Paykel Healthcare) (Fig. 3B) nasal pillow system is similar to the Swift ${ }^{\mathrm{TM}} \mathrm{FX}$ system as
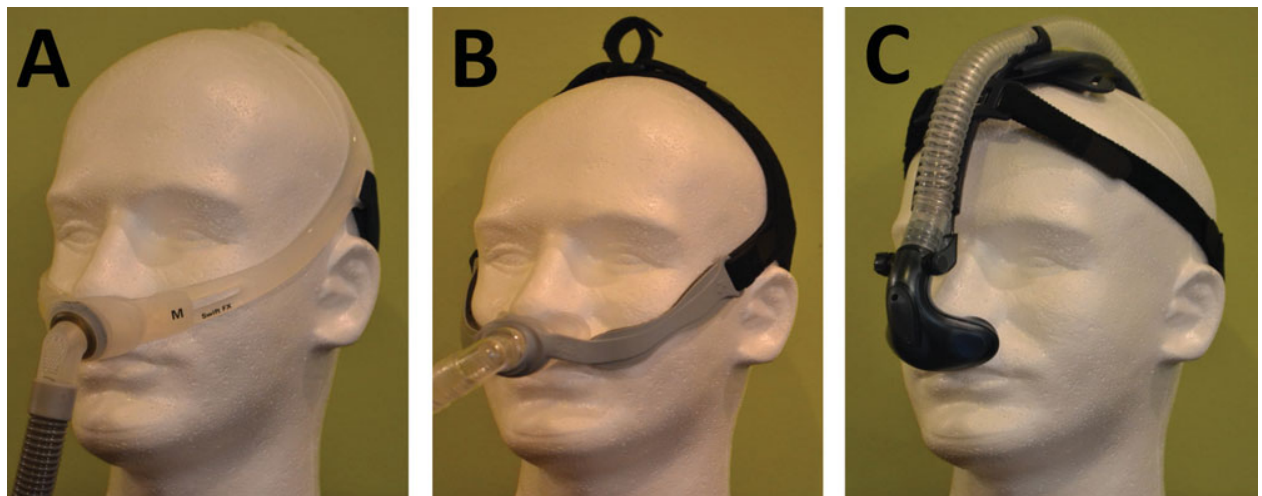

FIGURE 3. Nasal pillow masks. (A) Swift ${ }^{\mathrm{TM}}$ FX (ResMed); (B) Opus ${ }^{\mathrm{TM}} 360$ (Fisher \& Paykel Healthcare); (C) Breeze ${ }^{\circledR}$ SleepGear ${ }^{\circledR}$ nasal pillows (Covidien-Puritan Bennett ${ }^{\mathrm{TM}}$ ). 

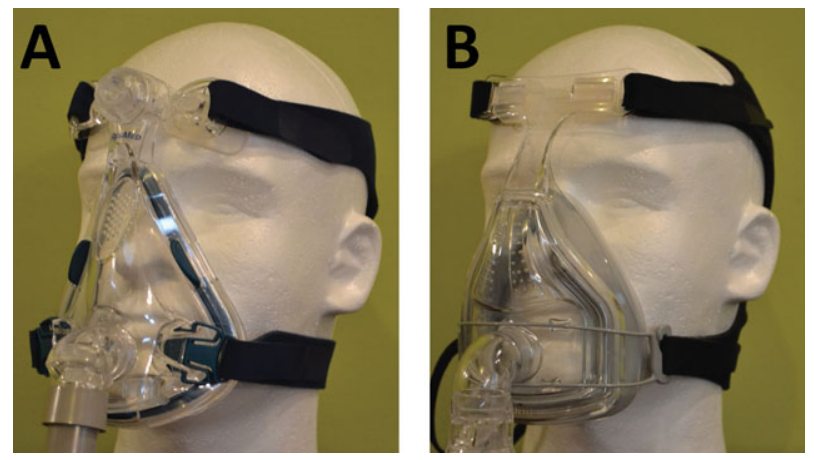

FIGURE 4. Oronasal (Full Face) masks. (A) Mirage Quattro ${ }^{\mathrm{TM}}$ (ResMed); (B) Forma ${ }^{\mathrm{TM}}$ (Fisher \& Paykel Healthcare).

a small nasal pillow system with tubing that can freely rotate. We have also had success with the Breeze $^{\circledR}$ SleepGear ${ }^{\circledR}$ (Covidien-Puritan Bennett ${ }^{\mathrm{TM}}$ ) (Fig. 3C) nasal pillow system that uses a bracket rather than straps to secure to the head and can often allow the user to put the system in place with one limb. The nasal pillow systems are also small enough to allow patients to wear eye glasses while the mask is in place. In our experience, some patients find the nasal pillow systems irritate the nose, are not secure enough to the face or head, or just seem to leak despite adjustments. In these situations, we use a nasal mask.

The nasal mask systems have more pressure points on the face, are generally larger than a nasal pillow system, and usually require a piece of the mask to go over the bridge of the nose such that the patient cannot wear eye glasses. We have had success with the Zest ${ }^{\mathrm{TM}}$ (Fisher \& Paykel Healthcare) (Fig. 2B). Many find it to be quite comfortable, as it uses a foam cushion that seems to be lighter than the gel or silicone cushions used in other nasal masks. The Mirage ${ }^{\mathrm{TM}} \mathrm{FX}$ (ResMed) (Fig. 2A) is a new mask that is lightweight with a very thin piece that goes over the bridge of the nose that we have found useful. The Breeze ${ }^{\circledR}$ SleepGear $^{\circledR} \quad$ (Covidien-Puritan Bennett) system (Fig. 2C) can be changed from nasal pillows to a nasal mask using the same bracket type of head gear. When a nasal mask is fitted initially, the straps are adjusted; but once in place the patient should be able to use quick-release clips to take the mask on and off. An alternative to clips is the ability to slide the pre-adjusted straps in place to improve ease of mask application. In the category of oronasal masks, we have had the most success with the Mirage Quattro ${ }^{\mathrm{TM}}$ (ResMed) full face mask system Fig. 4A).

\section{Conclusion}

1 The nasal, nasal pillow, and oronasal mask interfaces (Figs. 2-4) can all be used with NIV therapy for ALS patients.
2 Consider starting with a nasal pillow interface (Fig. 3), as these interfaces are light-weight and are the most comfortable. If the patient complains of nasal irritation or air leaks despite nasal pillow adjustment, then consider a light-weight nasal mask interface (Fig. 2).

3 Choice of mask interface also depends on ease of applying and removing the mask interface.

4 Masks/interfaces can be replaced as often as every 6 months (per Medicare).

E. NIV- Ordering, Monitoring and Troubleshooting. Mask Side Effects. In a cohort of 40 patients with chronic respiratory failure from either pulmonary or neuromuscular disease, the most common side effects of NIV (bi-level PAP or portable ventilator) included mouth or mask leaks in $43 \%$, skin irritation at the face mask interface in $23 \%$, nasal rhinitis or aerophagia in $13 \%$, and discomfort from the mask or headgear in $8 \%{ }^{48}$ Mask leaks that cause air to blow in the eyes suggest the mask is too big or fitted too loosely and needs to be refit and/or re-sized. See Table 3 for trouble shooting measures for NIV mask interfaces.

ALS patients with bulbar weakness are at an higher risk for mouth leak. ALS patients with bulbar-onset disease and bulbar dysfunction are less tolerant to NIV therapy. ${ }^{10,26,49,50}$ Although the mechanisms of NIV intolerance in ALS patients with bulbar dysfunction have not been systematically assessed, mouth leak from bulbar weakness is a possible cause of intolerance. NIV requires the tongue to be juxtaposed to the palate to prevent upper airway pressure from escaping into the oral cavity. Mouth leak has been associated with unintentional awakenings resulting in sleep fragmentation $^{51}$ that may impair NIV intolerance. The NIV machine may sense the leak and compensate with increased air pressure by means of the nasal mask in an attempt to maintain adequate tidal volume. This increased pressure applied to the nasal mucosa may result in inflammation and increased nasal resistance, diminished tidal volumes, and NIV intolerance. ${ }^{52}$ ALS patients may not be aware of mouth leak. Bed partners should be queried about the patient opening his or her mouth with NIV usage. Signs and symptoms of mouth leak may include oral cavity insufflation with cheek expansion, lip vibration as air escapes, nasal congestion, or dry mouth. Treatment of mouth leak would include a chin $\operatorname{strap}^{53}$ to prevent mouth opening or use of a full face mask (Fig. 4). Once leak has been minimized with either a chin strap or full face mask, heated humidification should be used to reduce nasal resistance and improve comfort. ${ }^{52}$ Sialorrhea is likely to be more common in ALS 
Table 3. NIV trouble-shooting.

\begin{tabular}{ll}
\hline Problem & Sofit or resize mask \\
\hline Mask leak & Implement use of chin strap \\
Mouth leak & Use oronasal (full face) mask that seals over both nose and mouth \\
Skin irritation at mask interface with the face & Adjust fit if mask is too tight \\
& Change to a smaller mask i.e. nasal pillow interface that has less facial contact \\
& If skin breakdown is present - switch to a non-latex mask or implement \\
& more frequent washing if using silicone mask \\
Nasal rhinitis and/or congestion & Add heated humidification to reduce dryness \\
Water dripping from mask/tube & Nasal steroids to reduce mucosal swelling \\
& Adjust humidification system by reducing the heat setting \\
& Place machine lower than the head of patient to keep water condensation \\
Aerophagia & from flowing into mask \\
& Simethicone to reduce abdominal discomfort and bloating \\
Mask head gear discomfort & Reduce IPAP pressure as tolerated \\
& Change head gear \\
& Switch to mask with less pressure points on face i.e. nasal pillows \\
\hline
\end{tabular}

patients with bulbar dysfunction and may decrease NIV tolerance. ${ }^{54}$ The 2009 AAN practice parameter provides the clinician with guidance regarding treatments for sialorrhea. ${ }^{55}$

Ideally at the time of NIV initiation, the provider should allow the ALS patient to view and try several NIV masks to determine which mask is preferable. The ALS clinician may choose to have a spare set of NIV masks in the ALS clinic for the patient to view at the time NIV is ordered.

Difficulty Falling Asleep with NIV. Falling asleep with a mask strapped to the head with an NIV machine blowing air into the nose can be difficult for patients. We first recommend assessing that the mask is not leaking and is comfortable as outlined in Table 3. To optimize initiation of sleep while using NIV, the ALS patient may need a distraction. We suggest listening to music or in some cases watching television while the NIV is in place to divert the patient's attention away from NIV to improve the initiation of sleep. The patient should be instructed to put the NIV in place when significantly sleepy to improve the likelihood of falling asleep with NIV. This would include avoiding daytime naps without the NIV that may reduce the ability to fall asleep at bedtime with NIV. In some patients prone to poor sleep initiation when starting NIV, a sleep aid medication may be considered. Amitriptyline is a consideration, particularly if it is also used to treat pseudobulbar symptoms or sialorrhea. Trazodone or temazepam are alternative sleep aid medications. Once the patient adjusts to NIV, the medication can be tapered. A third method would be to initiate a ramp of the pressure settings with the NIV machine. All bi-level PAP machines have the ability to start IPAP at a pressure lower than the target IPAP, to be ramped up to the goal IPAP pressure over 10 to $45 \mathrm{~min}$. As the ALS patient adjusts to NIV, the ramp can be shortened and eventually discontinued.

NIV Air Pressure Discomfort. The ALS patient may complain that the NIV device provides positive airway pressure when it is not wanted. Assess if the patient was trying to talk, cough or yawn, as this could result in enough air movement that the NIV machine is triggered to provide IPAP. Instruct the patient to avoid talking with NIV use until the symptom resolves. If using $\mathrm{S} / \mathrm{T}$ mode, decrease the breath per minute rate or consider a trial of NIV in $\mathrm{S}$ mode. If administering NIV with a mechanical ventilator, decrease the sensitivity of the inspiratory flow trigger.

The ALS patient may complain that the NIV does not provide enough air pressure with inspiration. Assess if the tubing is connected to the machine and mask interface properly, assess if there any holes in the tubing or mask interface tubing, and replace as needed. Make sure the air intake of the NIV machine is not blocked. If a bacterial filter is used, assess whether the filter is wet, as this will obstruct air flow. Make certain the mask interface is applied properly on the nose. If it is not applied over the nose properly, the patient will not receive adequate pressure support. Assess whether the patient has nasal congestion and consider medical treatment (see Table 3). If the above are excluded, then consider an increase in IPAP pressure, as the patient may have worsening respiratory muscle function and require more pressure support. If the patient complains that he or she cannot exhale adequately while using NIV, reduce EPAP to lowest possible setting, often $4 \mathrm{~cm}$ of $\mathrm{H}_{2} \mathrm{O}$.

The ALS clinician may initially troubleshoot NIV intolerance by means of phone conversation. However, if the patient has significant respiratory 
symptoms, troubleshooting will require the clinician to view the NIV machine and mask interface to improve NIV tolerance and compliance with therapy. If the clinician cannot troubleshoot the NIV intolerance issue over the phone and the patient is not unstable, the clinician should contact the patient's NIV medical equipment provider to send a respiratory therapist to the patient's home to troubleshoot the NIV.

NIV Ordering. The initial NIV order requires documentation of the diagnosis of ALS (ICD-9 $335.20)$ and $\mathrm{FVC}<50 \%$, or MIP $<-60 \mathrm{~cm}$ of $\mathrm{H}_{2} \mathrm{O}$, or $\mathrm{PaCO}_{2} \geq 45 \mathrm{mmHg}$ to meet Medicare requirements. For bi-level devices, the initial order should also state the mode ( $\mathrm{S}$ or $\mathrm{S} / \mathrm{T}$ ) and the breath per minute (BPM) rate if $\mathrm{S} / \mathrm{T}$ mode is used, the mask interface type, and humidification system. We also routinely prescribe a chin strap. The respiratory therapist setting up the NIV can determine the size of the mask interface for the patient's facial anatomy. If ordering a portable mechanical ventilator as the NIV device there are more options for ventilator mode. We frequently prescribe the synchronized intermittent mandatory ventilation/pressure support (SIMV/PS) mode or the Assist Control mode $(\mathrm{A} / \mathrm{C})$. The prescription should specify a pressure support (equivalent to IPAP minus EPAP) and PEEP (positive end-expiratory pressure) (equivalent to EPAP), and respiratory rate (equivalent to breath per minute rate) if desired. The respiratory therapist setting up the portable mechanical ventilator can then adjust the flow trigger and inspiratory and expiratory times to optimize comfort.

NIV Usage Monitoring. ALS patient NIV compliance should be assessed at each clinic visit. The ALS clinician can obtain objective NIV usage information by interrogating the NIV machine directly or downloading information from a NIV data card stored in the machine. Both the NIV machine and data card provide information that differentiates between usage hours, when the patient put on the NIV mask and was breathing with the machine, versus machine hours, when the NIV machine was turned on but not used by the patient. The data card provides more specific information about the time of the day or night when NIV was used, average usage hours per day, number of days with more than 4 hours of daily usage, etc. Downloading information from an NIV data card will require device manufacture software to be downloaded on a computer with a peripheral device that can read the NIV data card. The NIV data card reports can be stored either electronically and/or printed. The ALS clinician may request the respiratory therapist providing the NIV machine obtain the card data for review. Once the data have been downloaded, the data card can be re-used. One study demon- strated that weekly NIV downloads were associated with reduced ALS patient hospitalizations and emergency department visits. ${ }^{56}$ Thus far it is unclear if more frequent assessments of NIV usage than routine clinic visits are beneficial to improve NIV compliance or ALS patient quality of life and survival. However, the ALS clinician should be aware that NIV setting changes appear to be more frequent within the first year after starting NIV $^{8}$ and before the development of complete NIV compliance defined as $>6 \mathrm{~h}$ per 24 -h period. ${ }^{56}$

Alternatively, many of the current bi-level NIV devices have the capability to connect by means of a modem to a Web-based data management system provided by the NIV device manufacture. Examples of these data systems include EncoreAnywhere $^{\mathrm{TM}}$ by means of wired modem (Phillips Respironics) and ResTraxx ${ }^{\mathrm{TM}}$ by means of wireless module (ResMed). These electronic data systems allow the ALS clinician to download NIV compliance information as well as the ability to upload NIV prescription changes to perform NIV therapy by means of telemedicine. A recent study using the GoodKnight 425ST bi-level NIV device (Tyco Healthcare Group LP, California, USA) demonstrated significantly reduced clinic and emergency room visits and inpatient hospitalizations in those ALS patients who used weekly telemonitoring of NIV rather than standard clinic visit assessment that consisted of one office visit 2-3 weeks after starting NIV and every 3 months thereafter. ${ }^{56}$ The authors did not find a difference in NIV compliance or survival between the 2 groups, but the study was a small, pilot study. Nevertheless, this technology does currently exist. An interested ALS clinician should contact the representative of the NIV device manufacture and/or durable medical equipment provider of the NIV device to set up a web-based NIV data management system.

\section{Conclusion}

1 Many patients face NIV or NIV accessory challenges. There are simple solutions to many of the problems, as outlined in Table 3.

2 Troubleshooting NIV requires the ALS clinician to be knowledgeable about the equipment and communicate with the respiratory therapist providing the NIV equipment.

3 NIV device usage should be assessed at clinic visits. Weekly monitoring of NIV usage after device initiation may avoid unnecessary hospitalizations and emergency room visits.

\section{MECHANICAL INSUFFLATION-EXSUFFLATION}

Background. NIV assists weakened respiratory muscles of inspiration to maintain adequate gas 
exchange. However, ALS patients may also develop inadequate expiratory muscle function to perform an adequate cough. The cough reflex requires both inspiratory and expiratory muscle function and is necessary to clear airway secretions that can impair adequate airflow and subsequent gas exchange. The cough reflex starts with a deep inspiration to generate insufflation of $85-95 \%$ of the total lung capacity. The glottis and vocal cords then close the airway. The abdominal muscles and other expiratory muscles contract to further increase the intrathoracic pressure, and air is expelled rapidly with glottis and vocal cord relaxation. The air expelled with a cough can be measured as the peak cough expiratory flow (PCF), and normal levels are greater than $6 \mathrm{~L} / \mathrm{s} .{ }^{57} \mathrm{PCF}$ can be easily measured in the clinic with a peak flow meter. Alternatively, the PCF is measured with spirometry as part of the FVC maneuver. In this situation, the terminology changes, and the measurement becomes a peak expiratory flow rate (PEFR) or maximum forced expiratory flow $\left(\mathrm{FEF}_{\mathrm{Max}}\right)$ measured as either $\mathrm{L} / \mathrm{s}$ or $\mathrm{L} / \mathrm{min}$.

Adequate cough expiratory flow of $2.7 \mathrm{~L} / \mathrm{s}$ $(>160 \mathrm{~L} / \mathrm{min})$ has been reported as the minimum requirement to be effective to clear the airway of secretions and food particles in patients with neuromuscular diseases, including ALS. ${ }^{58,59}$ However, in the setting of a respiratory tract infection, airway secretions increase and an even higher PCF is need to adequately clear the airway. In ALS patients a PCF $<4.25 \mathrm{~L} / \mathrm{s}(<255 \mathrm{~L} / \mathrm{min})$ was predictive $(P<$ $0.001)$ of an ineffective cough, defined as patient self-report of inability to cough up mucus, abnormal breath sounds, dyspnea or oxygen desaturation during an upper respiratory tract infection. ${ }^{60}$ The mechanical insufflation-exsufflation (MI-E) device simulates a cough by first providing positive airway pressure at a relatively high pressure of $40-45 \mathrm{~cm}$ $\mathrm{H}_{2} \mathrm{O}$ for a few seconds to result in maximum inspiration. The machine is then suddenly switched to negative $40-45 \mathrm{~cm} \mathrm{H}_{2} \mathrm{O}$ of airway pressure to generate a sudden, high volume of expiratory air flow similar to a physiological cough to clear the airway of secretions and mucus. The patient is instructed to cough with exsufflation. In this way, the patient will maximize synchrony with the MI-E by closing the glottis at the end of inspiration to maximize intrathoracic pressure just before the forced expiration. In ALS patients naïve to NIV, MI-E significantly increased mean PCF in both those with severe bulbar symptoms, 178 to $212 \mathrm{~L} / \min$ (a 19\% increase $[P<0.05])$ and in those with few bulbar symptoms, 217 to $264 \mathrm{~L} / \mathrm{min}$ (a $21 \%$ increase $[P<$ $0.001])$. The increase was even more dramatic in both bulbar (36\% increase) and nonbulbar $(60 \%$ increase) ALS patients with PCF $<160 \mathrm{~L} / \mathrm{min}^{61}$

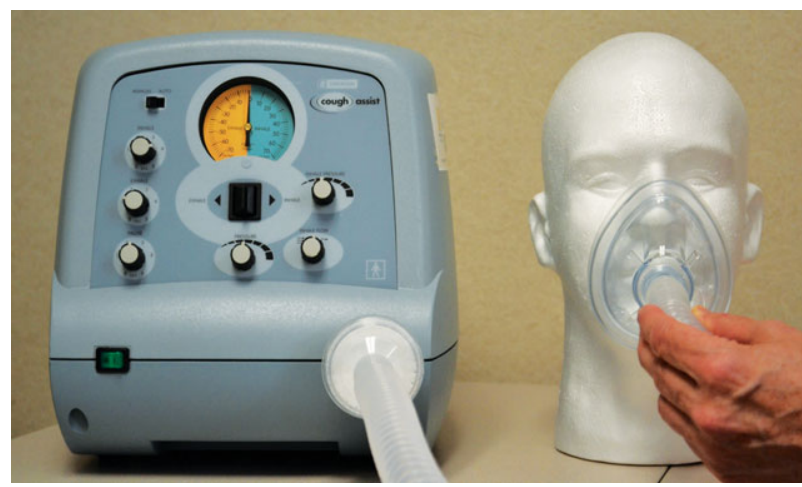

FIGURE 5. Mechanical insufflation-exsufflation device (Philips Respironics).

The U.S. Food and Drug Association approved the use of an MI-E device in 1993. Medicare and private insurance companies often cover the cost of MI-E in patients with a neuromuscular diagnosis such as ALS and PCF $<300-350 \mathrm{~L} / \mathrm{min}(5-6 \mathrm{~L} / \mathrm{s})$.

Bach et al. demonstrated that patients with severe respiratory muscle weakness from Duchenne muscular dystrophy with a $\mathrm{VC}<1$ liter and PCF $<4.5 \mathrm{~L} / \mathrm{s}$ could be trained to use both NIV and MI-E at home. ${ }^{58}$ Both NIV and MI-E were used as needed if daytime oxygen saturation dropped below $95 \%$. Use of MI-E with NIV in this patient population was associated with lower rates of hospitalization than patients using tracheostomy and mechanical ventilation. ${ }^{58} \mathrm{~A}$ similar protocol of combined NIV and MI-E used as needed to keep daytime oxygen saturation above $94 \%$ reduced hospitalizations in a cohort of 71 patients with a variety of neuromuscular disorders, including 4 with ALS. $^{62}$

MI-E Initiation. The provider should consider prescribing MI-E when the PCF is less than 255-270 $\mathrm{L} / \mathrm{min}(<4.25-4.5 \mathrm{~L} / \mathrm{s})$, and the ALS patient reports symptoms of a respiratory tract infection, inability to cough up mucus, or the ALS clinician detects abnormal breath sounds (crackles). MI-E may need to be avoided in ALS patients with known bullous emphysema, pneumothorax, or pneumomediastinum.

The MI-E machine circuit consists of an oronasal mask attached to the machine with a single tube and a bacteria/virus filter (Fig. 5). The MI-E machine can be used with a tracheostomy with an adapter. Inhalation pressures cannot be set higher than exhaled pressures. The mask is held over the nose and mouth with a good seal to prevent leaks. The MI-E machine is switched, either manually or automatically, to the inhale position for $2-3 \mathrm{~s}$ then rapidly switched to the exhale position for 1-3 seconds. The ALS patient is instructed to cough when the machine is switched in the exhale position. 
After exsufflation, the patient is given a 2- to 4-s pause as the MI-E device is switched to the neutral position to complete a single coughing cycle. This process is then repeated for a total of 4-6 coughing cycles to complete one MI-E sequence. After an MI-E sequence the patient should rest for $30 \mathrm{~s}$. More than 6 cycles per MI-E sequence may put the patient at risk of developing symptoms of hyperventilation. A suction device may be needed to remove thick secretions from the oral or upper airway. The patient then repeats this process for a total of 4-6 MI-E sequences, resting between each sequence, to complete a full MI-E treatment.

We recommend at least 3 to 4 MI-E treatments a day with 5 MI-E sequences that each include 5 coughing cycles, with 1 treatment performed just before bedtime or before NIV usage. With respiratory tract infections and symptoms of chest congestion or mucus plugging, the treatments can be increased to once or twice an hour to improve symptoms and maintain oxygen saturations above $94 \% .^{62}$

MI-E Pressure Settings. When initiating MI-E therapy, the initial pressure settings should be set to +15 for insufflations and $-15 \mathrm{~cm} \mathrm{H}_{2} \mathrm{O}$ for exsufflation, and gradually increased by 5 to $10 \mathrm{~cm} \mathrm{H}_{2} \mathrm{O}$ increments to a goal of +40 and $-40 \mathrm{~cm} \mathrm{H}_{2} \mathrm{O}$. A minimum of +35 and -35 are needed for complete airway secretion removal. If needed, the pressures can be increased further to a maximum +60 and $-60 \mathrm{~cm} \mathrm{H}_{2} \mathrm{O}$.

Winck et al. tested a variety of MI-E pressure settings in a cohort of ALS patients. ${ }^{63}$ Thirteen ALS patients were studied; 10 reported severe bulbar symptoms and 11 were using NIV. After 6 cycles of MI-E use at $+40 /-40$, the mean PCF increased from 170 to $200 \mathrm{~L} / \min (P<0.0005)$, mean oxygen saturation increased from $94 \%$ to 98\% $(P<0.005)$, and patients reported symptomatic improvement as measured by the Borg dyspnea score. Lower MI-E settings of $+15 /-15$ and $+30 /-30 \mathrm{~cm} \mathrm{H}_{2} \mathrm{O}$ did not result in significant improvement in PCF or oxygenation.

MI-E Intolerance. It is important for the provider to understand that ALS patients with significant bulbar dysfunction may have limitations that prevent a maximal increase of PCF with MI-E. ALS patients with advanced lower cranial motor neuronopathies may have impaired closure of the glottis and vocal cords. Impaired glottis closure will result in inability to maintain adequate lung volumes with insufflation. Therefore, the ALS patient with inadequate glottis closure will never maintain a large lung volume required for adequate expiratory air flow with exsufflation. Secondly, pharyngeal dilator muscles may become too weak to maintain adequate force to keep the upper airway open during exsufflation. The increased negative airway pressure applied with exsufflation may cause weakened pharyngeal dilator muscles to collapse and thereby occlude airflow to prevent adequate exsufflation. ${ }^{64}$ In these situations, tracheostomy may need to be considered.

\section{Conclusions}

1 Consider using MI-E in asymptomatic ALS patients with peak flow $<160 \mathrm{~L} / \mathrm{min}(2.7 \mathrm{~L} / \mathrm{s})$ to assist in clearance of airway secretions and debris.

2 Consider using MI-E in ALS patients with symptoms of impaired management of airway secretions with peak flow $<255-270 \mathrm{~L} / \mathrm{min}(4.25-4.5$ $\mathrm{L} / \mathrm{s}$ ).

3 Goal MI-E pressures are $+40 \mathrm{~cm} \mathrm{H}_{2} \mathrm{O}$ for insufflation and $-40 \mathrm{~cm} \mathrm{H}_{2} \mathrm{O}$ for exsufflation, given that $+35 /-35$ are the minimum pressures needed to clear airway secretions, and $+40 /-40$ significantly improve oxygen saturation and PCF in ALS patients.

4 Initial prescription should include: Cough assist device, 4 treatments a day and as needed, 5 coughing cycles per sequence followed by $30 \mathrm{~s}$ of rest, and 5 sequences for each treatment. Initial pressures of +15 and -15 gradually increased to a goal of +40 and $-40 \mathrm{~cm} \mathrm{H}_{2} \mathrm{O}$ are reasonable.

5 In the setting of an upper respiratory tract infection, MI-E can be used to maintain daytime oxygen saturation above $94 \%$.

\section{BREATH STACKING AND MANUAL ASSISTED COUGH}

Breath stacking and manually assisted cough techniques are alternatives to MI-E to improve PCF. With breath stacking, multiple inspiratory volumes occur without expiration. The subsequent inspiratory volumes summate or stack to result in a larger lung volume to be used with a subsequent spontaneous or manual assisted cough. Breath stacking requires the patient be able to voluntarily close the glottis between inspiratory efforts to prevent loss of inspired volume. This may be difficult for the ALS patient. Alternatively, expiration can be occluded with a one-way valve that only allows airflow with inspiration. With valved maneuvers, breath stacking can increase inspired volumes by $15-20 \% .^{65}$ Given that inspiratory muscles are likely to be weak when breath stacking is considered to augment PCF, the inspired volumes can be manually provided with a resuscitation bag. The resuscitation bag is connected by means of a short segment of tubing to a one-way valve that is connected either to a mouth piece or mask that goes over the nose and mouth in the case of lip closure weakness. ${ }^{66}$ 
Breath stacking has been demonstrated to increase PCF in ALS patients by approximately $50 \mathrm{~L} / \mathrm{min}$, and this effect lasted for $30 \mathrm{~min}$ after the procedure. $^{67}$ This is in agreement with a previous study that demonstrated breath stacking improved mean PCF from $1.81 \mathrm{~L} / \mathrm{s}$ to $3.37 \mathrm{~L} / \mathrm{s}$ in patients with a variety of neuromuscular disorders. ${ }^{68}$ The manual assisted cough technique requires a trained therapist or family member to lean over the partially supine patient, using one forearm to apply downward pressure on the chest while the other hand applies an abdominal thrust at the time of expiration. ${ }^{57,69}$ The combination of breath-stacking and manual assisted cough improves peak cough flow more than breath-stacking alone. ${ }^{68,69}$ When MEP is $>34 \mathrm{~cm} \mathrm{H} \mathrm{H}_{2} \mathrm{O}$, manual assisted cough is inferior to spontaneous cough, and the added benefit of breath stacking may be diminished when MEP $>34$ cm $\mathrm{H}_{2} \mathrm{O}$ or $\mathrm{VC}>1.9$ liters. ${ }^{69}$ However, unlike manual assisted cough, there is no ceiling effect with breath stacking in that it does not appear to be inferior to spontaneous cough when the patient has a high MEP or VC. ${ }^{69}$ When VC is $<340 \mathrm{ml}$, MEP $<14 \mathrm{H}_{2} \mathrm{O}$ or unassisted $\mathrm{PCF}$ is $<90 \mathrm{~L} / \mathrm{min}$ these manual methods are not likely to provide adequate cough assistance, and MI-E should be considered. ${ }^{69}$ Additionally, when MI-E was compared with combined breath stacking and manual assisted cough, MI-E resulted in a significantly higher mean PCF $(7.47 \mathrm{~L} / \mathrm{s})$ than the combined manual techniques $(4.27 \mathrm{~L} / \mathrm{s}){ }^{68}$ Manual assisted cough can be labor intensive for the care provider, should be avoided in patients with Greenfield filters, and should be used with caution in those with recent abdominal surgery, abdominal feeding tubes or at high risk of rib fractures. ${ }^{68}$ In contrast, breath stacking appears to be without significant side-effects. It is easy to administer with low cost items, and it is more portable than an MI-E machine.

\section{Conclusions}

1 Consider using valved breath stacking maneuvers with or without manual assisted cough to improve the clearance of airway secretions and debris when MI-E is unavailable.

2 Manual assisted cough is not beneficial when $\mathrm{MEP}>34 \mathrm{~cm} \mathrm{H}_{2} \mathrm{O}$.

\section{HIGH FREQUENCY CHEST WALL OSCILLATION}

Another approach to assist with secretion clearance is to apply mechanical forces to the chest wall to physically loosen airway secretions, move them from distal to more proximal airways and thereby facilitate coughing them out. Manual chest percussion with postural drainage is the traditional approach to mobilize secretions, but this can be very difficult for ALS patients with limited mobility due to diffuse weakness. Additionally, manual chest percussion places additional burdens on caregivers. A newer method for secretion mobilization is high frequency chest wall oscillation (HFCWO). Several companies now manufacture vests coupled to pneumatic compressors that deliver rapidly reversing oscillatory pressure to the chest wall. These high frequency chest wall oscillation vests have become standard for individuals with cystic fibrosis ${ }^{70}$ but there is relatively limited research on their use in ALS. Chaisson and colleagues performed a randomized trial of high frequency oscillation in 9 subjects with ALS. ${ }^{71}$ They did not find any significant differences in survival or decline in FVC with high frequency chest wall oscillation, though it is unlikely that this small study was sufficiently powered to assess these endpoints. Lange, Lechtzin, et al. performed a multicenter randomized trial of high frequency chest wall oscillation in 46 individuals with ALS. ${ }^{72}$ They found that subjects assigned to high frequency chest wall oscillation had less breathlessness than the control group. The 2009 AAN Practice Parameter update stated there were insufficient data to support or refute HFCWO for clearing airway secretions in patients with ALS. ${ }^{14}$ Anecdotally, some clinicians report a high rate of success combining MI-E and high frequency chest wall oscillation. In theory this is a logical approach, but it has not been systematically tested thus far.

\section{DIAPHRAGM PACER}

Investigators have considered the possible role of diaphragmatic pacing stimulators (DPS), which requires intramuscular implantation of electrodes in ALS, to postpone the need for invasive mechanical ventilation. A single study enrolled 16 patients with ALS and provided percutaneous gastric feeding tube and DPS placement simultaneously. The mean FVC was 59\%, and some used nocturnal NIV at the time of DPS placement. The study showed that the FVC rate of decline was $2.4 \%$ per month before surgery and $0.9 \%$ per month after the surgery. ${ }^{73}$ This very small, nonrandomized study suggests the need for further study of diaphragmatic pacing in the management of ALS. Given the limited data available, it is uncertain whether DPS is helpful, harmful, or has no effect in ALS. DPS has received FDA approval for a humanitarian use device exemption. With this type of FDA approval, the device does not require scientific evidence of efficacy to be marketed by the device manufacture. The manufacture's application, however, must contain sufficient information for the FDA to 
determine that the device does not pose an unreasonable or significant risk of illness or injury, and that the probable benefit to health outweighs the risk of injury or illness from its use.

\section{Conclusions}

1 Randomized, controlled trials are needed before DPS should be adopted into routine clinical practice.

2 DPS is not a replacement for NIV.

VI. TRACHEOSTOMY WITH MECHANICAL VENTILATION When to Consider Tracheostomy With Mechanical Ventilation. Tracheostomy with mechanical ventilation should be considered urgently for symptoms of respiratory failure when ALS patients are intolerant to NIV or despite maximal usage of NIV and MI-E. Intolerance of NIV or failure of NIV is generally due to the inability to clear respiratory secretions. This usually occurs in the setting of severe bulbar weakness. When daytime pulse oximetry remains $<95 \%$ despite maximal therapy with NIV and MI-E, 94\% of ALS patients require tracheostomy or die within the next 2 months. ${ }^{74}$ Therefore, ALS patients should be engaged in conversation regarding semi-urgent, elective tracheostomy with mechanical ventilation when daytime oxygen saturation is $<95 \%$ despite maximal use of respiratory therapies. If the ALS patient does not desire tracheostomy with mechanical ventilation, then NIV and MI-E therapies can be continued and additional comfort care initiated.

Before respiratory failure, the optimal time to engage the ALS patient in a discussion regarding tracheostomy and mechanical ventilation remains uncertain. However, we make a point of trying to have this conversation with all ALS patients so they can make an informed decision and outline advanced directives. It would be reasonable for the ALS clinician to initiate a discussion regarding tracheostomy when: (1) the patient uses NIV $>12 \mathrm{~h}$ in a 24-h time period (i.e., the patient is using NIV more often than not using it) or (2) the patient is intolerant of NIV, and FVC $<50 \%$ or symptoms of dyspnea. ALS patients may directly ask what to expect at the end of life and consider tracheostomy out of fear of suffocating to death. However, when caregivers are queried, they report a majority of ALS patients, 63-98\%, die peacefully. ${ }^{75-77}$ Slightly less than a third of patients were alert and communicating shortly before death while the majority, $73 \%$, were asleep or unresponsive ${ }^{77}$ presumably from hypoxic-hypercarbic encephalopathy. Symptoms of dyspnea and anxiety are reported in $25-36 \%$ of ALS patients ${ }^{75,77}$ and may require treatment with benzodiazepines and/or morphine. We find sharing this information is important to allevi- ate any misconceptions about the end-stages of ALS.

ALS Patient Factors Associated With Undergoing Tracheostomy. ALS patients undergoing tracheostomy are more often men, younger, have higher income, have young children or hold the belief that choosing a tracheostomy would allow for future treatments that may cure the disease. ${ }^{75,78-81}$ Tracheostomies are often initiated in an emergent situation. $^{75,78,79,81,82}$ This may be because ALS patients who undergo tracheostomy do not have advanced directives ${ }^{82}$ and are less likely to receive information about impending respiratory failure. ${ }^{79}$ However, it can be a difficult decision for some ALS patients to decide upon elective tracheostomy and the decision is put off until acute respiratory failure develops.

\section{ALS Patient Outcomes After Tracheostomy.}

Survival. Although tracheostomy with mechanical ventilation will avoid death from respiratory failure, it is not associated with indefinite survival. When tracheostomy is initiated for respiratory failure, the median survival ranges from $<12$ months to 37 months. ${ }^{75,81-83}$ The most common cause of death is respiratory tract infections. ${ }^{81-83}$ The tracheostomy site itself is a conduit for respiratory tract infections, and despite the use of a mechanical ventilator, mucus plugs and removal of excess secretions may become problematic. In a multivariable analysis use of enteral nutrition, age $<45$ years, follow-up at an ALS center, and being married were associated with longer survival after tracheostomy. ${ }^{81}$

Quality of Life. When ALS patients are queried after tracheostomy, a vast majority, $>80 \%$, report a positive perception of tracheostomy with ventilation, indicate they would have the procedure again, and recommend it to other ALS patients. ${ }^{78,79,82,84}$ ALS patients with tracheostomy were more satisfied living at home ${ }^{78}$ and reported more happiness if they were able to communicate or leave their home to participate in social activities. $^{84}$ However, one study reported that over 3 years' time there was a modest decrease in overall quality of life satisfaction after tracheostomy. ${ }^{80}$

Over time, as many as $50-70 \%$ of ALS patients with tracheostomy will have minimal communication ability or become locked-in. ${ }^{80,85}$ One study noted that $42 \%$ of ALS patients would want to stop long-term mechanical ventilation if they lose the ability to communicate, and most patients wanted to place limits on long-term mechanical ventilation with advanced directives. ${ }^{78}$ Advanced planning is likely to have a beneficial effect on communication between the patient and caregivers. ${ }^{78}$ Additionally, 
although a majority of ALS patients reported they were satisfied with tracheostomy, as many as $20 \%$ were not satisfied and requested that the ventilator be discontinued. In this scenario the ALS clinician may be in the position of discontinuing mechanical ventilation per the request of the ALS patient. If patient consent for tracheostomy ventilation is withdrawn and terminal weaning from the ventilator is initiated, Borasio and Voltz recommend sedation with a bolus of 2-4 mg midazolam before ventilator discontinuation then a bolus of 5-10 $\mathrm{mg}$ of morphine followed by a morphine infusion of half of the bolus dose per hour during the ventilator weaning with repeated bolus or increased infusion rate as needed for any signs of distress. ${ }^{86}$

In contrast to ALS patients, caregivers of patients who receive home mechanical ventilation with tracheostomy report decreased quality of life and express a great deal of frustration and unhappiness. ${ }^{78-80,84}$ Caregiver distress continued despite full-time aides, ${ }^{80}$ with $30 \%$ of caregivers reporting lower quality of life than the ALS patients for whom they provided care. Only 50\% would consider tracheostomy for themselves. ${ }^{79}$ Caregivers who spent time outside of the home and took care of their own needs were more likely to adjust. ${ }^{84}$

\section{Conclusions}

1 Daytime oxygen desaturation $<95 \%$ in patients using optimized NIV and MI-E is a useful indicator of impending respiratory failure and consideration of tracheostomy with mechanical ventilation. Battery operated finger pulse oximeters can be purchased for a nominal fee for home use.

2 After tracheostomy with mechanical ventilation for respiratory failure, median ALS patient survival is around 1-3 years. Respiratory infections are the most common cause of death.

3 Most ALS patients who underwent tracheostomy would choose the procedure again, but quality of life and ability to communicate effectively may wane over time. Advanced directives before tracheostomy likely improve communication and preserve ALS patient autonomy.

4 Caregivers of ALS patients with tracheostomy and mechanical ventilation report poor quality of life and may require significant psychosocial support.

\section{REFERENCES}

1. Kurian KM, Forbes RB, Colville S, Swingler RJ. Cause of death and clinical grading criteria in a cohort of amyotrophic lateral sclerosis cases undergoing autopsy from the Scottish Motor Neurone Disease Register. J Neurol Neurosurg Psychiatry 2009;80:84-87.

2. Corcia P, Pradat PF, Salachas F, Bruneteau G, Forestier N, Seilhean $\mathrm{D}$, et al. Causes of death in a post-mortem series of ALS patients. Amyotroph Lateral Scler 2008;9:59-62.

3. Bergofsky EH. Respiratory failure in disorders of the thoracic cage. Am Rev Respir Dis 1979;119:643-669.
4. De Troyer A, Borenstein S, Cordier R. Analysis of lung volume restriction in patients with respiratory muscle weakness. Thorax 1980;35:603-610.

5. Pinto AC, Evangelista T, de Carvalho M, Alves MA, Sales Luis ML. Respiratory assistance with a non-invasive ventilator (Bipap) in MND/ALS patients: survival rates in a controlled trial. J Neurol Sci 1995;129(Suppl):19-26.

6. Aboussouan LS, Khan SU, Meeker DP, Stelmach K, Mitsumoto H. Effect of noninvasive positive-pressure ventilation on survival in amyotrophic lateral sclerosis. Ann Intern Med 1997;127:450-453.

7. Kleopa KA, Sherman M, Neal B, Romano GJ, Heiman-Patterson T. Bipap improves survival and rate of pulmonary function decline in patients with ALS. J Neurol Sci 1999;164:82-88.

8. Gruis KL, Brown DL, Lisabeth LD, Zebarah VA, Chervin RD, Feldman EL. Longitudinal assessment of noninvasive positive pressure ventilation adjustments in ALS patients. J Neurol Sci 2006;247:59-63.

9. Bourke SC, Tomlinson M, Williams TL, Bullock RE, Shaw PJ, Gibson GJ. Effects of non-invasive ventilation on survival and quality of life in patients with amyotrophic lateral sclerosis: a randomised controlled trial. Lancet Neurol 2006;5:140-147.

10. Bourke SC, Bullock RE, Williams TL, Shaw PJ, Gibson GJ. Noninvasive ventilation in ALS: indications and effect on quality of life. Neurology 2003;61:171-177.

11. Lyall RA, Donaldson N, Fleming T, Wood C, Newsom-Davis I, Polkey MI, et al. A prospective study of quality of life in ALS patients treated with noninvasive ventilation. Neurology 2001;57:153-156.

12. Carratu P, Spicuzza L, Cassano A, Maniscalco M, Gadaleta F, Lacedonia D, et al. Early treatment with noninvasive positive pressure ventilation prolongs survival in Amyotrophic Lateral Sclerosis patients with nocturnal respiratory insufficiency. Orphanet J Rare Dis 2009; $4: 10$

13. Miller RG, Rosenberg JA, Gelinas D, Mitsumoto H, Newman D, Sufit $\mathrm{R}$, et al. Practice parameter: the care of the patient with amyotrophic lateral sclerosis (an evidence-based review): report of the Quality Standards Subcommittee of the American Academy of Neurology: ALS Practice Parameters Task Force. Neurology 1999;52:1311-1323.

14. Miller RG, Jackson CE, Kasarskis EJ, England JD, Forshew D, Johnston W, et al. Practice parameter update: the care of the patient with amyotrophic lateral sclerosis: drug, nutritional, and respiratory therapies (an evidence-based review): report of the Quality Standards Subcommittee of the American Academy of Neurology. Neurology 2009; $73: 1218-1226$

15. Clinical indications for noninvasive positive pressure ventilation in chronic respiratory failure due to restrictive lung disease, COPD, and nocturnal hypoventilation-a consensus conference report. Chest 1999;116:521-534.

16. Bradley WG, Anderson F, Gowda N, Miller RG. Changes in the management of ALS since the publication of the AAN ALS practice parameter 1999. Amyotroph Lateral Scler Other Motor Neuron Disord 2004;5:240-244.

17. De Troyer A, Kirkwood PA, Wildon TA. Respiratory action of the intercostal muscles. Physiol Rev 2005;85:717-756.

18. Goldman MD, Loh L, Sears TA. The respiratory activity of human levator costae muscles and its modification by posture. J Physiol 1985; 362:189-204.

19. De Troyer A, Sampson MG. Activation of the parasternal intercostals during breathing efforts in human subjects. J Appl Physiol 1982;52: 524-529.

20. Loring SH. Action of human respiratory muscles inferred from finite element analysis of rib cage. J Appl Physiol 1992;72:1461-1465.

21. de Carvalho M, Pinto S, Swash M. Association of paraspinal and diaphragm denervation in ALS. Amyotroph Lateral Sclerosis 2010;11: 63-66.

22. Uldry C, Fitting JW. Maximal values of sniff nasal inspiratory pressure in healthy subjects. Thorax 1995;50:371-375.

23. ATS/ERS Statement on respiratory muscle testing. Am J Respir Crit Care Med 2002;166:518-624.

24. Fallat RJ, Jewitt B, Bass M, Kamm B, Norris FH Jr. Spirometry in amyotrophic lateral sclerosis. Arch Neurol 1979;36:74-80.

25. Schiffman PL, Belsh JM. Pulmonary function at diagnosis of amyotrophic lateral sclerosis. Rate of deterioration. Chest 1993;103: 508-513.

26. Gruis KL, Brown DL, Schoennemann A, Zebarah VA, Feldman EL. Predictors of noninvasive ventilation tolerance in patients with amyotrophic lateral sclerosis. Muscle Nerve 2005;32:808-811.

27. Lechtzin N, Wiener CM, Shade DM, Clawson L, Diette GB. Spirometry in the supine position improves the detection of diaphragmatic weakness in patients with amyotrophic lateral sclerosis. Chest 2002; 121:436-442.

28. Mendoza M, Gelinas DF, Moore DH, Miller RG. A comparison of maximal inspiratory pressure and forced vital capacity as potential criteria for initiating non-invasive ventilation in amyotrophic lateral sclerosis. Amyotroph Lateral Scler 2007;8:106-111. 
29. Lyall RA, Donaldson N, Polkey MI, Leigh PN, Moxham J. Respiratory muscle strength and ventilatory failure in amyotrophic lateral sclerosis. Brain 2001;124:2000-2013.

30. Hart N, Polkey MI, Sharshar T, Falaize L, Fauroux B, Raphael JC, et al. Limitations of sniff nasal pressure in patients with severe neuromuscular weakness. J Neurol Neurosurg Psychiatry 2003;74: $1685-1687$.

31. Beck M, Giess R, Wurffel W, Magnus T, Ochs G, Toyka KV. Comparison of maximal voluntary isometric contraction and Drachman's hand-held dynamometry in evaluating patients with amyotrophic lateral sclerosis. Muscle Nerve 1999;22:1265-1270.

32. Pinto A, De CM, Evangelista T, Lopes A, Sales-Luis L. Nocturnal pulse oximetry: a new approach to establish the appropriate time for non-invasive ventilation in ALS patients. Amyotroph Lateral Scler Other Motor Neuron Disord 2003;4:31-35.

33. Lechtzin N, Scott Y, Busse AM, Clawson LL, Kimball R, Wiener CM. Early use of non-invasive ventilation prolongs survival in subjects with ALS. Amyotroph Lateral Scler 2007;8:185-188.

34. Jaye J, Chatwin M, Dayer M, Morrell MJ, Simonds AK. Autotitrating versus standard noninvasive ventilation: a randomised crossover trial. Eur Respir J 2009;33:566-571.

35. Navalesi P, Fanfulla F, Frigerio P, Gregoretti C, Nava S. Physiologic evaluation of noninvasive mechanical ventilation delivered with three types of masks in patients with chronic hypercapnic respiratory failure. Crit Care Med 2000;28:1785-1790.

36. Lechtzin N, Weiner CM, Clawson L. A fatal complication of noninvasive ventilation. N Engl J Med 2001;344:533.

37. Bach JR, Alba AS. Management of chronic alveolar hypoventilation by nasal ventilation. Chest 1990;97:52-57.

38. Gay PC, Edmonds LC. Severe hypercapnia after low-flow oxygen therapy in patients with neuromuscular disease and diaphragmatic dysfunction. Mayo Clin Proc 1995;70:327-330.

39. Melo J, Homma A, Iturriaga E, Frierson L, Amato A, Anzueto A, et al. Pulmonary evaluation and prevalence of non-invasive ventilation in patients with amyotrophic lateral sclerosis: a multicenter survey and proposal of a pulmonary protocol. J Neurol Sci 1999;169: 114-117.

40. Roberts F. Respiratory physiology. Update in Anaesthesia 2000;1-3.

41. Hillberg RE, Johnson DC. Noninvasive ventilation. N Engl J Med 1997;337:1746-1752.

42. Berry RB, Chediak A, Brown LK, Finder J, Gozal D, Iber C, et al. Best clinical practices for the sleep center adjustment of noninvasive positive pressure ventilation (NPPV) in stable chronic alveolar hypoventilation sundromes. J Clin Sleep Med 2010;6:491-509.

43. Peysson S, Vandenberghe N, Philit F, Vial C, Petitjean T, Bouhour F, et al. Factors predicting survival following noninvasive ventilation in amyotrophic lateral sclerosis. Eur Neurol 2008;59:164-171.

44. Butz M, Wollinsky KH, Wiedemuth-Catrinescu U, Sperfeld A, Winter $\mathrm{S}$, Mehrkens $\mathrm{HH}$, et al. Longitudinal effects of noninvasive positivepressure ventilation in patients with amyotrophic lateral sclerosis. Am J Phys Med Rehabil 2003;82:597-604.

45. Janssens JP, Howarth-Frey C, Chevrolet JC, Abajo B, Rochat T. Transcutaneous PC02 to monitor noninvasive mechanical ventilation in adults: assessment of a new transcutaneous PC02 device. Chest 1998; 113:768-773.

46. Chai CL, Pathinathan A, Smith B. Continuous positive airway pressure delivery interfaces for obstructive sleep apnoea. Cochrane Database of Systematic Reviews 2006(4)CD005308. DOI: 10.1002/ 14651858.CD005308.pub2.

47. Brown DL, Concannon M, Kaye AB, Zupancic M, Lisabeth LD. Comparison of two headgear systems for sleep apnea treatment of stroke patients. Cerebrovasc Dis 2009;27:183-186.

48. Criner GJ, Brennan K, Travaline JM, Kreimer D. Efficacy and compliance with noninvasive positive pressure ventilation in patients with chronic respiratory failure. Chest 1999;116:667-675.

49. Aboussouan LS, Khan SU, Banerjee M, Arroliga AC, Mitsumoto H. Objective measures of the efficacy of noninvasive positive-pressure ventilation in amyotrophic lateral sclerosis. Muscle Nerve 2001;24: 403-409.

50. Lo Coco D, Marchese S, Pesco MC, La Bella V, Piccoli F, Lo Coco A. Noninvasive positive-pressure ventilation in ALS: predictors of tolerance and survival. Neurology 2006;67:761-765.

51. Meyer TJ, Pressman MR, Benditt J, McCool FD, Millman RP, Natarajan R, et al. Air leaking through the mouth during nocturnal nasal ventilation: effect on sleep quality. Sleep 1997;20:561-569.

52. Tuggey JM, Delmastro M, Elliott MW. The effect of mouth leak and humidification during nasal non-invasive ventilation. Respir Med 2007;101:1874-1879.

53. Bachour A, Hurmerinta K, Maasilta P. Mouth closing device (chinstrap) reduces mouth leak during nasal CPAP. Sleep Med 2004;5: 261-267.

54. Cooper-Knock J, Ahmedzai SH, Shaw P. The use of subcutaneous glycopyrrolate in the management of sialorrhoea and facilitating the use of non-invasive ventilation in amyotrophic lateral sclerosis. Amyotroph Lateral Scler 2011;12:464-465.
55. Miller RG, Jackson CE, Kasarskis EJ, England JD, Forshew D, Johnston W, et al. Practice parameter update: the care of the patient with amyotrophic lateral sclerosis: multidisciplinary care, symptom management, and cognitive/behavioral impairment (an evidence-based review): report of the Quality Standards Subcommittee of the American Academy of Neurology. Neurology 2009;73:1227-1233.

56. Pinto A, Almeida JP, Pinto S, Pereira J, Oliveira AG, de Carvalho M. Home telemonitoring of non-invasive ventilation decreases healthcare utilisation in a prospective controlled trial of patients with amyotrophic lateral sclerosis. J Neurol Neurosurg Psychiatry 2010;81 $1238-1242$.

57. Bach JR. Update and perspective on noninvasive respiratory muscle aids. Part 2: the expiratory aids. Chest 1994;105:1538-1544.

58. Bach JR, Ishikawa Y, Kim H. Prevention of pulmonary morbidity for patients with Duchenne Muscular Dystrophy. Chest 1997;112: 1024-1028.

59. Bach JR. Amyotrophic lateral sclerosis: predictors for prolongation of life by noninvasive respiratory aids. Arch Phys Med Rehabil 1995 $76: 828-832$.

60. Sancho J, Servera E, Diaz J, Marin J. Predictors of ineffective cough during a chest infection in patients with stable amyotrophic latera sclerosis. Am J Respir Crit Care Med 2007;175:1266-1271.

61. Mustfa N, Aiello M, Lyall RA, Nikoletou D, Olivieri D, Leigh PN, et al. Cough augmentation in amyotrophic lateral sclerosis. Neurology 2003;61:1285-1287.

62. Tzeng AC, Bach JR. Prevention of pulmonary morbidity for patients with neuromuscular disease. Chest 2000;118:1390-1396.

63. Winck JC, Goncalves MR, Lourenco C, Viana P, Almeida J, Bach JR. Effects of mechanical insufflation-exsufflation on respiratory parameters for patients with chronic airway secretion encumbrance. Chest 2004;126:774-780.

64. Sancho J, Servera E, Diaz J, Marin J. Efficacy of mechanical insufflation-exsufflation in medically stable patients with amyotrophic lateral sclerosis. Chest 2004;125:1400-1405.

65. Baker WL, Lamb VJ, Marini JJ. Breath-stacking Increases the depth and duration of chest expansion by incentive spirometry. Am Rev Respir Dis 1990;141:343-346.

66. Robinson R. 'Breath stacking' reported to make swallowing safer in ALS. Neurol Today 2011;11:12.

67. Cleary S, Misiaszek J, Wheeler S, Kalra S, Johnston W. Using lung volume recruitment therapy to improve swallowing and airway pretection for individuals with ALS. Amyotroph Lateral Scler 2011; 11(Suppl 1):58

68. Bach JR. Mechanical Insufflation Exsufllation. Comparison of peak expiratory flows with manually assisted and unassisted coughing techniques. Chest 1993;104:1553-1562.

69. Toussaint M, Boitano LJ, Gathot V, Steens M, Soudon P. Limits of effective cough-augmentation techniquest in patients with neuromuscular disease. Respir Care 2009;54:359-366.

70. Yankaskas JR, Marshall BC, Sufian B, Simon RH, Rodman D. Cystic fibrosis adult care: consensus conference report. Chest 2004;125. 1S-39S

71. Chaisson KM, Walsh S, Simmons Z, Vender RL. A clinical pilot study: high frequency chest wall oscillation airway clearance in patient with amyotrophic lateral sclerosis. Amyotroph Lateral Scler 2006;7 107-111.

72. Lange DJ, Lechtzin N, Davey C. High-frequency chest wall oscillation in ALS: an exploratory randomized, controlled trial. Neurology 2006;67:991-997.

73. Onders RP, Elmo M, Khansarinia S, Bowman B, Yee J, Road J, et al. Complete worldwide operative experience in laparoscopic diaphragm pacing: results and differences in spinal cord injured patients and amyotrophic lateral sclerosis patients. Surg Endosc 2009;23:1433-1440.

74. Bach JR, Bianchi C, Aufiero E. Oximetry and indications for tracheotomy for amyotrophic lateral sclerosis. Chest 2004;126:1502-1507.

75. Bradley MD, Orrell RW, Clarke J, Davidson AC, Williams J, Kullmann $\mathrm{DM}$, et al. Outcome of ventilatory support for acute respiratory failure in motor neuron disease. J Neurol Neurosurg Psychiatry 2002;72. $752-756$.

76. Kuhnlein P, Kubler A, Raubold S, Worrell M, Kurt A, Gdynia H-J, et al. Palliative care and circumstances of dying in German ALS patients using non-invasive ventilation. Amyotroph Lateral Scler 2008;9:91-98.

77. Neudert C, Oliver D, Wasner M, Borasio GD. The course of the terminal phase in patients with amyotrophic lateral sclerosis. J Neurol 2001;248:612-616.

78. Moss AH, Oppenheimer EA, Casey P, Cazzolli PA, Roos RP, Stocking $\mathrm{CB}$, et al. Patients with amyotrophic lateral sclerosis receiving longterm mechanical ventilation. Chest 1996;110:249-255.

79. Kaub-Wittemer D, von Steinbuchel N, Wasner M, Laier-Groeneveld G, Borasio GD. Quality of life and psychosocial issues in ventilated patients with amyotrophic lateral sclerosis and their caregivers. J Pain Symptom Manage 2003;26:890-896.

80. Rabkin JG, Albert SM, Tider T, Del Bene ML, O’Sullivan I, Rowland LP, et al. Predictors and course of elective long-term mechanical 
ventilation: a prospective study of ALS patients. Amyotroph Lateral Scler 2006;7:86-95.

81. Chio A, Calvo A, Ghiglione P, Mazzini L, Mutani R, More G. Tracheostomy in amyotrophic lateral sclerosis: a 10-year population-based study in Italy. J Neurol Neurosurg Psychiatry 2010;81:1141-1143.

82. Vianello A, Arcaro G, Palmieri A, Ermani M, Braccioni F, Gallan F, et al. Survival and quality of life after tracheostomy for acute respiratory failure in patients with amyotrophic lateral sclerosis. J Crit Care 2011;26:329.e7-329.e14.

83. Lo Coco D, Marchese S, La Bella V, Piccoli T, Lo Coco A. The amyotrophic lateral sclerosis functional rating scale predicts survival time in amyotrophic lateral sclerosis patients on invasive mechanical ventilation. Chest 2007;132:64-69.

84. Gelinas DF, O'Connor P, Miller RG. Quality of life for ventilator-dependent ALS patients and their caregivers. J Neurol Sci 2008; 160 (Suppl 1):S134-S136.

85. Hayashi H, Oppenheimer EA. ALS patients on TPPV. Totally lockedin state, neurologic findings and ethical implications. Neurology 2003;61:135-137.

86. Borasio GD, Voltz R. Discontinuation of mechanical ventilation in patients with amyotrophic lateral sclerosis. J Neurol 1998;245 $717-722$. 